\title{
JOSÉ CARBONEL FOUGASSE (1707-1801). EL RASTRO DE UN ERUDITO EN LA ESPAÑA ILUSTRADA
}

\author{
Rosario Die Maculet \\ ARMANDO ALBEROLA ROMÁ \\ Universidad de Alicante
}

«Si veneras a los Amayas que te guíen en la ciencia sostenedora de los Estados, si buscas los Casiris y Carboneles que te hagan conocer otros hombres y otros países por medio de otros idiomas, si no te arredra la menos dulzura de los Sarmientos que te indiquen los inmensos espacios por donde corre la variedad de los talentos humanos; entonces es seguro que no darás lugar a la ociosidad cuyos momentos está espiando el seductor para corromperte; entonces verás lo insípido de todos los comunes placeres al lado del de la estimación universal de los buenos.»

(V. González Arnao: Elogio del Excelentísimo Señor Conde de Campomanes, 1803) ${ }^{1}$

Fecha de recepción: diciembre de 2009

Fecha de aprobación: febrero de 2010

Las palabras que encabezan estas páginas, pronunciadas por su autor en 1803 ante los Académicos de la Historia, evocan a cuatro maestros de Pedro Rodríguez

1. GonZÁlez ARNAO, V.: «Elogio del Excelentísimo Señor Conde de Campomanes, leído en Junta ordinaria del día 27 de mayo de 1803, por D.---, Académico de Número», Memorias de la Real Academia de la Historia, Madrid, 1817, T. V, p. 4. Cfr. en LAdero Quesada, M. A.: «Campomanes medievalista», en Anes Álvarez, G. (coord.): Campomanes en su II centenario, Madrid, 2003, p. 37. 
Campomanes; eruditos que en diferentes etapas de su vida le formaron intelectualmente, modelando su carácter y dejando su impronta en él. Hallamos en ellas al jurista Juan José Ortiz de Amaya, prestigioso abogado en cuyo bufete comenzó Campomanes su brillante carrera en el foro y donde amplió, asimismo, sus estudio de Historia y disciplina eclesiástica; al sabio orientalista Miguel Casiri², bibliotecario de El Escorial, con quien el asturiano cursó estudios de árabe; y al padre Martín Sarmiento, su mentor en cuestiones hermenéuticas y bibliográficas. El tercero de los citados, a quien premeditadamente hemos dejado para el final, es José Carbonel Fougasse ${ }^{3}$, maestro de griego de Campomanes y al mismo tiempo su condiscípulo en las clases de árabe impartidas por Casiri.

Carbonel fue uno de esos personajes tan atractivos como olvidados que proporcionó la Ilustración española, hombres dedicados en cuerpo y alma al estudio de las más diversas ramas del saber, conocidos y respetados por su gran valía intelectual pero a quienes las circunstancias del tiempo que les tocó vivir frustraron todas sus expectativas y ahogaron sus aspiraciones, obligándoles a permanecer en un oscuro segundo plano y dilapidando así el gran potencial de sus conocimientos y habilidades. Ese sería el destino de José Carbonel, un hombre cuya erudición le llevó a relacionarse con muchas de las personalidades más sobresalientes de la España del XVIII hasta el punto de que, como veremos a lo largo de estas páginas, podemos encontrar su nombre citado en la correspondencia de un literato, de un historiador, de un político o de un científico ${ }^{4}$; entre

2. Mihail Garcieh al-Gaziri (Trípoli, 1708-† Madrid, 1791), monje sirio llegado a España bajo la protección del padre Rávago, confesor de Felipe V. Experto arabista, fue autor de la Biblioteca Hispano-Arabica Escurialensis.

3. La grafía de su segundo apellido experimenta múltiples alteraciones en los diversos documentos consultados apareciendo también escrito como Fogasa, Fogasse y Fause. Nosotros hemos optado por mantener la original francesa.

4. Para elaborar este estudio hemos manejado las cartas enviadas por José Carbonel a Campomanes y a Charles Le Maur, las de Campomanes a Felipe Samaniego y al padre Martín Sarmiento y las del Marqués de la Cañada al secretario de la Academia de la Historia, José Miguel de Flores (todas en Fundación Universitaria Española, Archivo Papeles Campomanes [en adelante FUE, APC]); las de José Carbonel, Eugenio Llaguno Amirola, José Miguel de Flores y Lorenzo Diéguez (en Real Academia de la Historia [RAH], Expediente de José Carbonel y Fogasse, leg. 129, carp. 45, sección 11D); Gregorio Mayans a Manuel Martí (en Biblioteca Archivo Histórico Mayansiano [BAHM]), Luis José Velázquez a Agustín Montiano (Biblioteca Nacional [BN], Mss. 17.546), Jorge Juan Santacilia al marqués de la Ensenada y a Miguel Múzquiz (Archivo General de Simancas [AGS], Marina, leg. 50 y 95) y Clas Alströmer a Carl Linné (Linnean Society. Londres, vol. IX, pp. 398-399, reproducidas por FERnÁndez PÉrez, J.: «Tres apóstoles de Linné en Cádiz: Pehr Ösbeck, Pehr Löfling y Clas Alströmer» en Pelayo LóPEZ, F. [ed.]: Pehr Löfling y la Expedición al Orinoco [1754-1761], Madrid, 1990, pp. 51-102). 
las páginas de un libro de medicina o literatura ${ }^{5}$ e, incluso, grabado con letras de molde en el epitafio de un ilustre marino ${ }^{6}$.

Carbonel fue un gran políglota tanto de lenguas vivas como clásicas y orientales, académico de la Historia, profesor de idiomas y bibliotecario de la Academia de Guardias Marinas de Cádiz, secretario de la Asamblea Amistosa Literaria que fundara el científico Jorge Juan Santacilia, y director de los estudios públicos de la ciudad gaditana. Poseía lo que, parafraseando a Voltaire, podríamos denominar un auténtico espíritu «pantófilo», pues su sed de conocimientos le llevó a cultivar otras ramas del saber como Matemáticas, Física, Filosofía, Astronomía, Náutica, Numismática y Ciencias Naturales. Como ya hemos dicho, su vasta erudición fue reconocida y valorada por renombrados intelectuales de su tiempo y, así, resulta oportuno traer a colación el emotivo testimonio del aprecio y respeto que el propio Campomanes sentía hacia su maestro y amigo y que dejó plasmado en su Ilustración al Periplo de Hannon donde, al exponer lo útil que resultaría disponer de una obra en la que se cotejara la ciencia náutica de los antiguos con los conocimientos modernos, elogiaba la figura de Carbonel en los siguientes términos:

Esta es una obra, que algunos años ha propuse a mi amigo Don Joseph Carbonel, de la Academia Real de la Historia, que a mi ver es uno de los sujetos más a propósito para tan útil y difícil empresa, por su conocimiento en las mathemáticas, en la antigüedad, y en

5. José Carbonel aparece citado elogiosamente en la obra de CANIVELL, F.: Tratado de Vendages, y Apositos para el uso de los Reales Colegios de Cirugia (...) por D.---, Ayudante de Cirujano Mayor de la Real Armada y Maestro de el Real Colegio de Cirugia de Cádiz. Barcelona; en la imprenta de Teresa Piferrer, viuda, en la Plaza del Ángel. Año 1763. Su autor, en la página 8 de la dedicatoria, dirigida a D. Pedro Virgili y fechada en Cádiz el 16 de octubre de 1762, afirma: "Quiero tambien confesar a V.S. que hasta he querido pedantear el estilo de mi Obra, y assi la he hecho revistar, corregir, y enmendar de los muchos defectos que tendría, saliendo de mis manos en la Ortographia, y voces castellanas por mi estimado amigo Don Joseph Carbonel, dignissimo Maestro en lenguas, y Bibliotecario de los Caballeros Guardias Marinas». También aluden a su erudición los padres RodRíGuez MoHEDANO, Fr. R. y Fr. P.: Historia Literaria de España desde su primera población hasta nuestros dias (...) por los PP. Fr.-- y Fr.---, Lectores de Theología (...), T. II, parte I, en Madrid, en la Imprenta de Francisco Xavier García, calle de los Capellanes, Año 1768, pp. 194-195, nota 8 donde los autores, al hablar de la etimología y origen de los artículos castellanos, reconocen deber dicha información a Carbonel: «El artículo español le, el, la, lo, no es derivado del Griego. El Castellano ha tomado de la lengua Teutónica la idea general y uso de los artículos; pero no los mismos artículos; pues estos son el pronombre latino ille, illa, illud, modificado o corrupto; según noticia que se ha dignado comunicarnos nuestro amigo Don Joseph Carbonel, Profesor de Mathematicas, Bibliotecario y Maestro de Lenguas en la Real Academia de Cavalleros Guardias Marinas de Cadiz, sujeto muy versado en estas materias y en todo género de literatura».

6. El epitafio que en 1773 se colocó en la tumba del marqués de la Victoria fue redactado por el viejo amigo de éste, José Carbonel, cuyo nombre figura al pie de la inscripción latina. Así lo refiere el marino e historiador José Vargas Ponce: «Con nueva solemnidad y nuevo panegírico se hizo la translación al monumento de mármol, que el amor, gratitud y memoria de los marinos erigió a su ilustre gefe, y al que decora un cumplido epitafio, que colocamos entre los apéndices, para extender el buen gusto y la tierna amistad de otro sabio octogenario (don Josef Carbonell) que lloroso se lo consagró». VARGAS PONCE, J.: Varones ilustres de la Marina Española. Vida de Don Juan Josef Navarro, marqués de la Victoria, Madrid, en la Imprenta Real, año de 1808, pp. 359-360, epígrafe 252 y epitafio en pág. 520. 
las lenguas orientales Hebrea, Arábiga, y Griega, y las más de las corrientes de Europa. El mérito de este Literato, y lo mucho, que le estimo me han dado oportuno lugar para dar noticia de su sobresaliente erudición, y juicio, y de lo útil, que sería al público continuasse este pensamiento a que le ví dispuesto; teniendo para ello, oportunidad y tiempo. ${ }^{7}$

Dos variables - oportunidad y tiempo- de las que Carbonel nunca pudo disponer a su voluntad pese a que fue la suya una vida larga que estuvo a punto de alcanzar el siglo. Las obligaciones que le imponían sus empleos, la agobiante escasez de medios y los avatares de la política, con las fulminantes destituciones de ministros, los cambios de gobierno y la inevitable paralización de proyectos, le impidieron incluso ver cumplida una de sus aspiraciones, como era la publicación de alguna de sus obras. Estos escritos, que permanecen inéditos ${ }^{8}$, son apenas una muestra de su incesante actividad intelectual y justifican el unánime reconocimiento que se le profesó en vida. Con todo, por satisfactoria que toda esta consideración pudiera resultarle a nivel personal, Carbonel se sintió siempre desaprovechado en sus talentos, relegado en un rincón del mundo «despoblado de libros y sabios» ${ }^{9}$, como definió a Cádiz, y desempeñando un puesto de «maestro» que consideraba muy inferior a sus aptitudes y desde el que intentó progresar con todos los medios a su alcance sin conseguirlo, pese a las continuas solicitudes que a lo largo de los años realizó ante aquellos a quienes, como Campomanes, consideraba sus amigos y protectores. De todo ello se lamentó Carbonel en no pocas ocasiones: "C'est mon sort d'être loué, aimé même, et entièrement négligé. $C$ 'est pour moi qu'Horace a dit: Virtus Laudatur et alget» ${ }^{10}$.

Algunos autores han esbozado pequeños retazos biográficos sobre José Carbonel a partir de los escasos datos que de él se conocían, siendo el primero de ellos el archivero decimonónico Pedro Roca quien, llevado por su interés hacia el personaje llegó a elaborar sendas monografías que la muerte le impidió concluir perdiéndose así, tal vez para siempre, valiosa información que habría contribuido a un mejor conocimiento

7. Rodríguez Campomanes, P: Antigüedad Marítima de la República de Cartago con el Periplo de su General Hannon, traducido del Griego e ilustrado, por D.---, Abogado de los Consejos, Assesor General de los Correos y Postas de España. En Madrid, en la imprenta de Antonio Pérez de Soto, 1756; la cita en pp. 74-75 de la Ilustración al Periplo de Hannon. Cfr. en GiL FernÁndeZ, L.: Campomanes. Un helenista en el poder, Madrid, 1976, p. 34, n. 19.

8. Las obras de Carbonel se conservan manuscritas, junto con las de otros autores, en BN, Mss. 11552, Papeles varios, 154 h.; Mss. 11553, Memorias leídas en la Asamblea Amistosa Literaria de Cádiz, 310 h.; y Mss. 11554, Papeles varios de Gramática Arábiga, 171 h. Una relación exhaustiva de todos sus escritos, agrupados según su temática, la encontramos en las páginas 234-235 de RUEDA MuÑOz DE SAN PEDRO, G.: «Un manuscrito del siglo XVIII referente a las antigüedades de Cádiz» en MANGAS, J. y AlVAR, J (eds.): Homenaje a José María Blázquez, Madrid, 1994, vol. II, pp. 227-235.

9. José Carbonel a Pedro Rodríguez Campomanes s/f s/d, FUE, APC, 37-27-2. La carta está publicada en Herrera Navarro, J. (ed.): Pedro Rodríguez Campomanes. Epistolario (1778-1802), Volumen II, Madrid, 2004, pp. 616-617.

10. «La virtud es alabada y, sin embargo, se desprecia». José Carbonel a Charles Le Maur, Cádiz 6-9-1757, en FUE, $A P C, 48 / 150$. 
sobre Carbonel ${ }^{11}$. De modo que, a día de hoy, el desconocimiento que todavía existe sobre su persona le envuelve hasta tal punto que su figura ha sido descrita muy gráficamente por Luis Gil como «un tanto evanescente» ${ }^{12}$. No obstante, la localización en diferentes archivos nacionales y extranjeros de documentos relativos a José Carbonel y a sus familiares ${ }^{13}$, así como la recopilación de interesantes testimonios que hasta ahora permanecían ignorados o dispersos, nos permiten efectuar un bosquejo biográfico sobre Carbonel que pretende ser un punto de partida para futuras investigaciones al iluminar la trayectoria vital de quien, sin duda, fue una personalidad relevante del círculo ilustrado.

\section{NACIMIENTO, FAMILIA Y AÑOS DE FORMACIÓN}

Pierre Joseph Carbonel Fougasse nació el 19 de marzo de 1707 en la localidad francesa de La Ciotat ${ }^{14}$, un pequeño enclave de marineros y pescadores situado entre

11. Referencias biográficas sobre Carbonel se encuentran, por orden cronológico, en ROCA LÓPEZ, P.: «Orígenes de la Real Academia de Ciencias Exactas, Físicas y Naturales (Historia científica del primer gobierno de Fernando VI)» en Homenaje a Menéndez y Pelayo en el año vigésimo de su profesorado. Estudios de erudición española con un prólogo de D. Juan Valera, Madrid, 1899, tomo II, pp. 845-940. En la nota 2 de la pág. 882 menciona la inminente publicación de dos trabajos suyos, «uno sobre la Academia Amistosa Literaria de Cádiz y su secretario D. José Carbonel, y otro acerca de los Carboneles»; el mismo anuncio aparece en los números de la Revista de Archivos, Bibliotecas y Museos correspondientes al mes de diciembre de los años 1897 y 1898 (pp. 668 y 609, respectivamente) sin que dichos artículos llegaran a ver la luz debido, quizás, a la repentina muerte de Roca en enero de 1903; Guillén TATo, J.: Nuevos datos sobre la Real Compañia de Caballeros Guardias Marinas de Cádiz, y sobre la estancia en ésta de su comandante, el capitán de navio de la Real Armada don Jorge Juan y Santacilia, Madrid, 1939, pág. 16; GIL FernándeZ, L.: Campomanes. Un helenista..., pp. 33-35; Pando Villarroya, J. L.: La Asamblea Amistosa Literaria, Madrid, 1984, pp. 38-41; RUEDA MUÑoz De SAN Pedro, G.: op. cit.; y VAllejo García HeVIA, J. Mª «Campomanes, la biografía de un jurista e historiador (1723-1802)» en Cuadernos de Historia del Derecho, Universidad Castilla-La Mancha, 1996, nº 3, p. 154.

12. GiL FernáNDEZ, L.: Campomanes. Un helenista..., p. 34.

13. La mayor parte de los datos relativos a los orígenes y circunstancias familiares de José Carbonel se contienen en sus dos testamentos otorgados en la Real Isla de León en 13 de septiembre de 1780 y 11 de junio de 1796 respectivamente (Archivo Histórico Provincial de Cádiz, San Fernando [AHPC-SF], Protocolos de José Gutiérrez de Morón, sig. 63: testamento de José Carbonel y Anastasia María Sánchez, ff. 347-351; y Protocolos de Bartolomé Canle Gómez, sig. 118: testamento de José Carbonel, ff. 539544). Agradecemos al coronel de Intendencia de la Armada don Jorge Juan Guillén Salvetti y al capitán de navío don Manuel Baturone Santiago la localización de los referidos documentos y su generosidad al ponerlos a nuestra disposición. Por otra parte, el expediente personal de Carbonel, custodiado en el Archivo General de la Marina «Álvaro de Bazán» (AGMAB), Intendencia, leg. 3268/48, nos aporta abundante información sobre su trayectoria profesional.

14. Registres deposés aux Archives de la Mairie de La Ciotat (AMLC), Département des Bouches du Rhone, Acte de naissance, 1707, p. 17v $\mathrm{v}^{\circ}$ : «Pierre Joseph Carbonel fils de Jean Augustin Anasthase Louis et de Mme. Marguerite Fougasse sa femme a eté baptissé a dix neuvieme mars mil sept cents sept, né le même jour. Le parrain a eté le Sr. Pierre Fougasse et la marraine Magdeleine Prepaud veuve du feu sieur Jean Brive grand mere maternelle en foi de quoi le pere absent la sousigné la marraine ayant dit ne pas ecrire». 
Marsella y Tolón. Su padre, Jean Augustin Carbonel Bonfigli, era originario de la ciudad italiana de Liorna mientras que su madre, Marguerite Fougasse, procedía de Marsella. Fruto de este matrimonio, que se celebró en la iglesia parroquial de La Ciotat el 27 de octubre de 1704, fueron al menos otros tres hijos: Antoine Claude, nacido el 18 de octubre de 1705; Anne, nacida el 11 de junio de 1708; y Elisabeth, de quien no hemos localizado el acta de nacimiento pero que consta como fallecida en edad infantil el 29 de junio de $1710^{15}$.

Sabemos, además, gracias a una instancia presentada por José Carbonel en 1785 solicitando la jubilación, que su padre sirvió en el ejército español durante cincuenta y dos años, los últimos cuarenta y dos como comisario de Guerra, empleo que obtuvo «en atención a la fidelidad, aplicación y secreto con que manejó diferentes dependencias del Real Servicio» ${ }^{16}$. El hecho de que en los archivos de La Ciotat no aparezcan datos sobre la familia con posterioridad a 1710 nos lleva a pensar que por esas fechas habían abandonado ya la localidad siguiendo al padre en sus desplazamientos. Ignoramos por tanto dónde transcurrió la infancia y adolescencia de José Carbonel, dónde curso sus estudios y dónde pudo adquirir los vastos conocimientos humanísticos que poseía. La única referencia que hemos encontrado al respecto se encuentra en una carta de Carbonel al ingeniero francés Charles Le Maur ${ }^{17}$ en la que afirma haber estudiado en la Academia de Orán, y haber sido condiscípulo en ella de «Mr. Tilly, Commandant l'Artillerie de cette Place, mon ancien condisciple dans l'Académie d'Oran, et mon ami particulier...» ${ }^{18}$.

Sin embargo, el citado comentario plantea un problema cronológico al intentar determinar la época en que esto se habría producido. Las dificultades derivan, en primer lugar, de la gran diferencia de edad existente entre Carbonel y Tilly, al ser este último quince años más joven; y, en segundo lugar, al considerar que dicha Academia fue creada poco despues de la reconquista de Orán, a finales de 1732, lo que deja muy

15. AMLC: Acte de mariage, 1704, p. 53; Actes de naissance, 1705, p. 104 y 1708, p. 57; Acte de mortuaire, 1710, p. 49.

16. AGMAB, Intendencia, leg. 3268/48: Expediente personal de José Carbonel Fogasa, Instancia de José Carbonel fechada en Isla de León el 2 de junio de 1785 solicitando su jubilación. Según la base de datos del grupo P.A.P.E. (Personal Administrativo y Político de España), que amablemente nos ha comunicado el profesor D. Francisco Andújar, el nombramiento de Juan Agustín Carbonel como comisario de guerra se produjo el 1 de julio de 1726, asignándosele un sueldo de 18.000 reales. También consta en dicha base que el referido Carbonel Bonfigli murió el 28 de abril de 1767, dejando como heredera universal de todos sus bienes a su viuda Elena Mafioti.

17. Le Maur (Francia, 1720-† Madrid, 1785) llegó a España en 1750 reclutado por Antonio de Ulloa, siendo incorporado al Ejército español como ingeniero militar. Sobre su trayectoria profesional ver SÁNCHEZ LÁZARO, T.: Carlos Lemaur y el canal de Guadarrama, Madrid 1995, 154 pp. + la redacción del proyecto de un canal navegable, 1785 (en facsímil).

18. José Carbonel a Charles Le Maur, Cádiz 6-9-1757, en FUE, APC 48/150. Rudesindo Everardo de Tilly y García de Paredes (Villalba, 1722-† Madrid, 1793) inició su carrera en el Ejército en 1737, participando en las campañas de Italia, Portugal, Buenos Aires y el sitio de Gibraltar. Llegó a Teniente General de Artillería, fue caballero de Santiago y miembro del Supremo Consejo de Guerra. En 1790 el rey le concedió el título de Conde de Tilly. Cfr. en Mercurio de España, enero de 1793, tomo I, p. 184. 
poco margen para la estancia en ella de José Carbonel pues, como veremos a continuación, éste se encontraba residiendo en Alicante en 1734. Precisamente su estancia en esta ciudad, documentada gracias a las manifestaciones contenidas en sus testamentos, es la que nos brinda una atrayente posibilidad respecto al lugar donde pudo recibir la sólida formación en lenguas clásicas que andando el tiempo le proporcionaría una bien ganada reputación de erudito.

Y ello es así porque en Alicante tuvo su residencia, durante los casi veinte años que van desde 1718 hasta 1737 , una personalidad tan destacada como Manuel Martí, deán de la alicantina Colegial de San Nicolás y figura clave del humanismo español del primer tercio del siglo XVIII ${ }^{19}$. También en ese mismo periodo de tiempo se estableció en la ciudad y desarrolló en ella una fecunda actividad artística el escultor Juan Bautista Borja, cualificado representante del barroco valenciano y autor de algunas de las más importantes obras con que cuenta Alicante, tales como la portada principal de la iglesia de Santa María, la fachada trasera del Ayuntamiento y la magnífica Capilla de la Comunión de la iglesia de San Nicolás ${ }^{20}$. La construcción de este último monumento, el más singular de todos por su suntuosidad y riqueza, se efectuó a partir de 1720 tras hacerse cargo Borja de la dirección de la obra la cual, a partir de ese momento, se realizó conforme a unos planteamientos estéticos y arquitectónicos propios del barroco italiano en los que, tal y como sugieren los expertos, tuvo una activa intervención el propio deán Martí $^{21}$. La relación de éste con el escultor fue muy estrecha, dada la afinidad de sus gustos en materia artística, y se prolongó hasta 1737, año en que murió Martí y en el que Juan Bautista Borja «se fue a vivir fuera»"22 abandonando definitivamente Alicante.

Apenas tres años antes, el dos de septiembre de 1734, José Carbonel había contraído matrimonio en la iglesia parroquial de San Nicolás de Alicante con María Francisca Borja Arroyos, hija del mencionado escultor y de su esposa Teresa Arroyos ${ }^{23}$.

19. Sobre Martí (Oropesa, 1663-†Alicante, 1737) resultan imprescindibles los trabajos de MESTRE SANCHIS, A. de entre los cuales señalamos Epistolario III, Mayans y Martí, Valencia, 1973, 465 pp.; Humanismo y crítica histórica en los ilustrados alicantinos, Alicante, 1980, 153 pp.; y Manuel Martí, el Deán de Alicante, Alicante, 2003, 364 pp.

20. Un esbozo biográfico de Juan Bautista Borja (Valencia, 1692-† id. 1756) en CEÁN BERMúdEZ, J. A.: Diccionario Histórico de los más ilustres profesores de las Bellas Artes en España, Madrid, 1800, T. I, p. 167. Su trayectoria artística está estudiada en SÁEZ VIDAL, J.: La ciudad de Alicante y las formas artísticas de la cultura barroca: 1691-1770, Alicante, 1985, 257 pp.

21. SÁEZ VidAL, J.: op. cit., p. 180.

22. Así consta en el padrón del Equivalente de 1737 del Archivo Municipal de Alicante (AMA): Libro 5, Arm. 7, Equivalente de los años 1735 a 1743, s.f.

23. Los datos relativos a su matrimonio se encuentran en sus testamentos ya citados. AHPC-SF, sig. 63, testamento de José Carbonel y Anastasia María Sánchez, Isla de León 13 de septiembre de 1780, ff. 347-351; y sig. 118, testamento de José Carbonel, Isla de León 11 de junio de 1796, ff. 539-544. Gracias a ellos nos ha sido posible localizar la inscripción en los libros parroquiales de la iglesia de San Nicolás de Alicante que se custodian en el Archivo Histórico de la Diócesis Orihuela-Alicante, Sección Alicante (ADOA-SA, SN): Libro de Desposados 1732-1737, f. 70: «En la ciutat de Alacant al segon dia del mes de setembre del any mil setsents trenta y quatre (...) es desposaren (...) de una part Joseph Carbonell fill 
Desconocemos los motivos que determinaron la llegada de Carbonel a la ciudad y la época de su vida en que esto se produjo aunque es lógico suponer que debió ser anterior en varios meses, e incluso años, a la celebración de sus esponsales. En cualquier caso, la coincidencia en la misma ciudad y en un mismo período de tiempo de dos personas tan significadas en el campo del helenismo como lo era en ese momento Manuel Martí y llegaría a serlo, salvando las distancias, José Carbonel; así como el hecho de que éste emparentara con Borja, precisamente durante los años en los que el escultor se encontraba realizando la Capilla de la Comunión de la iglesia de San Nicolás, nos lleva a concluir que por fuerza hubo de producirse algún tipo de contacto intelectual entre el deán y Carbonel, existiendo además la posibilidad de que fuera Martí quien iniciara a aquél en el estudio de las lenguas clásicas, al igual que lo hizo con otros muchos tal y como lo afirmaba el propio deán a Gregorio Mayans en abril de 1733:

Me alegro infinito que el amigo Corachá viva. No me acuerdo haverle enseñado el griego, como él dize. Bien sí, le he enseñado a don Joseph Rato, hoy obispo de Córdova, a don Phelipe Bolifón, a Miñana, y otros. ${ }^{24}$

No obstante, no hemos encontrado en las cartas de Martí referencia alguna a nuestro personaje, de ahí que el magisterio de Martí respecto a José Carbonel, que dejamos apuntado, no pase de ser una hipótesis al carecer, por el momento, de confirmación documental.

Por lo que se refiere a su enlace con María Francisca Borja, éste se celebró sin que mediaran las acostumbradas escrituras de capitulaciones matrimoniales que podrían aportar información sobre las circunstancias personales, profesionales o patrimoniales de los novios pues, tal y como manifiesta Carbonel en su último testamento, en su referido consorcio «no intervino por parte de ambos contrayentes dote ni capital alguno ${ }^{25}$. Sabemos, eso sí, que su unión fue fructífera y procrearon al menos cinco hijos. El nacimiento de los dos primeros, Tomasa y Juan, queda acreditado por los libros parroquiales de la iglesia de San Nicolás, donde fueron bautizados en septiembre de 1735 y mayo de 1737, respectivamente ${ }^{26}$. Ambos debieron morir de muy corta edad pues Carbonel no los menciona en sus testamentos, citando en cambio como nacidos de este matrimonio a otros tres hijos: el mayor, Antonio, quien andando el tiempo sería bibliotecario del Seminario de Nobles de Madrid y casaría con Francisca del Valle; Elena, que profesaría como monja en el convento de la Purísima Concepción de Lebrija; y María, que contraería matrimonio en Alicante con Bartolomé Fabra ${ }^{27}$.

de Juan Agusti Carbonell y de Margarita Fause, conjuges, natural de la ciutat de Marcella, en Francia, y de altra María Francisca Borgia, donsella, filla de Bautista Borgia y Theresa Arroyos, conjuges, natural y veina de dita ciutat y feligresa de la espresada parroquia (...)».

24. Manuel Martí a Gregorio Mayans, Alicante 24 de abril de 1733. Cfr. en MAYANS y SISCAR, G.: Epistolario III, Mayans y Martí, Valencia, 1973, pp. 285-289 (la cita en p. 286).

25. AHPC-SF, sig. 118, testamento de José Carbonel, Isla de León 11 de junio de 1796, fol. 540v.

26. ADOA-SA, SN: Libro Bautismos 1735-1737, ff. 71v-72 y 240v.

27. AHPC-SF, sig. 63, testamento de José Carbonel y Anastasia María Sánchez, Isla de León 13 de septiembre de 1780, ff. 347-351; y sig. 118, testamento de José Carbonel, Isla de León 11 de junio de 1796, ff. 539-544. 
Ninguno de ellos figura como bautizado en las iglesias alicantinas de San Nicolás o Santa María por lo que su nacimiento debió producirse cuando la familia había abandonado la ciudad siguiendo, quizá, los pasos del escultor Juan Bautista Borja ${ }^{28}$. Tal vez fueron estos años posteriores, de los que nada sabemos, los de su permanencia en la Academia de Orán, según apunta en su ya citada carta a Le Maur. Esto encajaría perfectamente en la trayectoria de Tilly quien, como queda dicho en nota más arriba, inició su servicio en el Ejército en 1737; pero no así para Carbonel cuya edad superaba ya con creces la media de un alumno ${ }^{29}$.

Nuevamente se pierde el rastro de José Carbonel de quien no volveremos a tener noticias hasta que algunos años después aparezca en Madrid, ya viudo. Una vez más son sus testamentos los que nos informan que el siete de octubre de 1744 contrajo segundas nupcias en la Villa y Corte con Anastasia María Sánchez, alumna del Real Colegio de San Antonio de los Portugueses ${ }^{30}$ e hija de don Alfonso Sánchez Labrador y de doña Wencisláa Martínez de Mora, ambos difuntos y todos naturales de la villa de La Guardia, en la Mancha ${ }^{31}$. Fruto de este matrimonio fueron otros dos hijos, Guillermo y Rafael, que encaminaron sus pasos hacia la vida militar e ingresaron en la Armada donde, como veremos más adelante, compartirían un aciago destino.

\section{MAESTRO DE PAJES Y ACADÉMICO DE LA HISTORIA}

Carbonel enfocó su vida profesional hacia la enseñanza, siendo su primer discípulo Juan Antonio Pérez Gamoneda, más adelante marqués del mismo nombre, a ins-

28. En los padrones del Equivalente de 1735 a 1740 aparecen censados dos individuos llamados Joseph Carbonell, uno residente en la calle Carnicerías y el otro en la calle San José. Este último ya no figura en el padrón de 1741. AMA, Libro 5, Armario 7, Equivalente de los años 1735 a 1743, s.f.

29. Es necesario advertir, no obstante, que José Carbonel declaró siempre una edad inferior en 6 ó 7 años a la que realmente tenía según su acta de nacimiento. Así se observa en la ya citada instancia de 1785 solicitando la jubilación en la que dice tener 72 años, en vez de los 78 que ya había cumplido (AGMAB, Intendencia, leg. 3268/48: Expediente personal de José Carbonel Fogasa). Asimismo, en su partida de defunción fechada el 9 de febrero de 1801 (Archivo de la Parroquia Castrense de San Francisco, Isla de León/San Fernando. Cádiz [APCSFC]: Libro de Difuntos n 3, partida de defunción 676, f. 101v) se hace constar que murió con 88 años de edad, dato sin duda aportado por la mujer que le atendió durante sus últimos años y que ésta debía conocer por habérselo oído al propio Carbonel pero que no coincide con los casi 94 años que habría cumplido apenas un mes después de su muerte.

30. El citado colegio, denominado de la Inmaculada Concepción y dirigido por la Hermandad del Refugio estaba unido a la iglesia de San Antonio de los Portugueses. Se dedicaba a la educación de niñas huérfanas, estando reputado en la época como el mejor establecimiento de la Corte por los auxilios que prestaba a los necesitados. Ver CRUZ, N. de la: Viage de España, Francia e Italia, Cádiz, 1812, tomo XI, pp. 66 y 67; también APARISI Mocholí, A.: La enseñanza en Madrid en el siglo XVIII, Madrid, 1978, p. 23.

31. AHPC-SF, sig. 63, testamento de José Carbonel y Anastasia María Sánchez, Isla de León 13 de septiembre de 1780, f. 348v; y sig. 118, testamento de José Carbonel, Isla de León 11 de junio de 1796, f. 540v. 
tancias de su tío don Juan Cascos ${ }^{32}$ quien, según declaraciones del propio Carbonel ${ }^{33}$, había sido su protector y gran amigo de su padre. Tal vez fue por influencia de este alto funcionario como consiguió, hacia 1743, un puesto de maestro en la «Real Casa de los Caballeros Pages de S.M» ${ }^{34}$, institución contigua a la Real Armería y en la que se educaban veinticuatro jóvenes caballeros ${ }^{35}$. Durante los nueve años que permaneció en dicha institución y a instancias del duque de Medina Sidonia, caballerizo mayor y director de la misma, Carbonel elaboró para uso de los alumnos:

...un método de enseñarles la Cosmografía y Geografía, combinadas con la Historia sagrada y profana, Mitología y Chronología; el de instruirlos en las Matemáticas, Física experimental y Dibuxo; y otro para la Lengua Francesa, aplicable a otro cualesquier idioma vivo... ${ }^{36}$

Desde su puesto como maestro de pajes estaba en disposición de frecuentar los círculos cultos de la Corte y muy pronto entró en relación con intelectuales y personajes influyentes que no tardaron en reconocer y apreciar sus méritos por lo que, apenas tres años más tarde, consiguió ingresar en la Real Academia de la Historia ${ }^{37}$. En su expediente personal consta que solicitó su incorporación por carta fechada en Madrid el 27 de marzo de 1747 en la que exponía que «hallándose con alguna erudiczión en las lenguas y la Historia» suplicaba ser recibido como académico. Al no encontrar el censor D. Martín de Ulloa ningún impedimento para ello, fue admitido como miembro honorario el 14 de abril y tomó posesión el día $28^{38}$.

32. Juan Cascos Villademoros (c. 1690- $\uparrow$ 1754) era archivero de la Primera Secretaría de Estado con grado de oficial tercero desde 1742 hasta 1747 en que fue nombrado secretario de la reina viuda Isabel de Farnesio. A su muerte, en enero de 1754 le sucedió su sobrino Juan Pérez Gamoneda. Cfr. OzANAM, D.: Les Diplomates Espagnols du XVIII siècle, Madrid, 1998, p. 222.

33. José Carbonel a Pedro Rodríguez Campomanes, s/f s/d, FUE, APC 37-27-2. Cfr. en Herrera NaVArRo, J. (ed.): op cit., pp. 616-617.

34. Carbonel, en su ya citada instancia de 1785, expone al Rey que «ha cerca de 42 años que tiene el honor de servirle (...) en la carrera del Magisterio, los nueve primeros en la Real Casa de Caballeros Pages» (AGMAB, Intendencia, leg. 3268/48: Expediente personal de José Carbonel Fogasa).

35. La Real Casa de Caballeros Pajes estaba en la parroquia de Santa María, en el palacio de los Guevara, y en ella los alumnos aprendían las primeras letras, Gramática, Retórica, Filosofía, Historia, Geografía y Matemáticas. Se les instruía también en Baile, Esgrima, lengua francesa, Violín y Equitación. Ver Enciclopedia Metodica. Artes Academicos, traducidos del Francés al Castellano, a saber, el Arte de la Equitación por Don Baltasar de Irurzun; y el del Bayle, de Esgrima y de Nadar, por Don Gregorio Sanz. En Madrid. En la Imprenta de Sancha. Año de MDCCXCI. Apéndice o suplemento a la palabra Caballeriza, p. 400. Esta institución se unió en 1786 al Real Seminario de Nobles.

36. AGMAB, Intendencia, leg. 3268/48: Expediente personal de José Carbonel Fogasa.

37. Memorias de la Real Academia de la Historia, 1796, T. I, p. CXXXVII.

38. RAH, Expediente de José Carbonel y Fogasse..., n 21. La Oración Gratulatoria se encuentra a continuación con el $\mathrm{n}^{\circ} 22$. Los Estatutos fundacionales de la RAH permitían veinticuatro miembros numerarios y otros tantos supernumerarios «juiciosos, decentes, bien opinados y de aplicación, è inclinación, a los travajos de la Academia». Junto a ellos, la Institución podía admitir un número indeterminado de miembros honorarios que se considerasen dignos de esa distinción. Cfr. NAVA RodríGuEZ, Ma T.: «La 
En esta época conoció a Pedro Rodríguez Campomanes el cual, con apenas veintitrés años y establecido ya en Madrid como abogado, había decidido aumentar sus conocimientos lingüísticos dedicándose al estudio del griego y el árabe, herramientas que consideraba imprescindibles para profundizar en la historia del derecho español ${ }^{39}$. La sólida reputación de que gozaba Carbonel como helenista debió ser la que movió a Campomanes a tomarle como maestro de Griego, iniciándose de ese modo una amistad de la que Carbonel se enorgulleció siempre y que hizo patente en todas sus cartas y escritos. Su magisterio sobre Campomanes es, sin duda, el dato biográfico más conocido de Carbonel así como el que, a partir de 1748, ambos estudiaron la lengua árabe con el presbítero libanés Miguel Casiri ${ }^{40}$, erudito orientalista llegado a España ese mismo año con el encargo de catalogar los códices árabes de El Escorial.

El círculo de amistades de Carbonel fue creciendo en estos años al ritmo de sus inquietudes intelectuales. Ignacio de Luzán, en el Proyecto de Academia General de Ciencias, Artes y Bellas Letras que elaboró hacia 1751 bajo el patrocinio del ministro José de Carvajal ${ }^{41}$, incluye una «Lista de sujetos que conozco y me parece pueden ser a propósito para Académicos» citando dentro de la categoría de miembros asociados a «Dn. Joseph Carbonel, maestro de los Pages del Rey; entiende varias lenguas, el griego, el arábigo y otras» ${ }^{42}$. Otros personajes como Juan de Iriarte, los padres Sarmiento y Flórez o Luis José Velázquez, le trataron con asiduidad, franqueándole el acceso a sus celdas y tertulias ${ }^{43}$. A ellas acudía Carbonel acompañado de su hijo mayor, Antonio

Real Academia de la Historia como modelo de unión formal entre el Estado y la cultura (1735-1792)» en Cuadernos de Historia Moderna y Contemporánea, Madrid, 1987, nº 8, pp. 127-155.

39. Gil FernÁndez, L.: Campomanes. Un helenista en el poder, p. 33.

40. Prueba de ello son las anotaciones que se encuentran en algunos manuscritos de Carbonel conservados en BN, Mss. 11554, Papeles varios de Gramática Arábiga. Así, el nº 1, titulado Elementos de la Gramática Arábiga, por Dn. Joseph Carbonel y Fogassa, Comisario de Marina, Discípulo de Dn. Miguel Rasir, Syro. Se empezó el día $1^{\circ}$ de Junio de 1748. En Madrid; el no 2, titulado Composiciones Arábigas, por el Comisario de Marina Dn. Joseph Carbonel Fogassa, Discípulo de Dn. Miguel Casiri, Presbitero Syro, uno de los Bibliotecarios del Rei $n r^{\circ}$ Señor. En el año de 1748, en compañía de Dn. Pedro Campomanes, oi (en 1788) Gobernador Ynterino del Consejo, y Conde de Campomanes. En el $\mathrm{n}^{\circ} 4$, titulado Apuntaciones sobre la escritura Arábigo-Cúfica, Carbonel afirma que él y Casiri fueron quienes lograron descifrar por primera vez en España dicha escritura, manifestando al respecto: «Creo q. la $1^{a}$ inscripc $^{o} n$ Arabigo-Cufica q. se logró descifrar en España, fue la q. se encontró en Tortosa, año de 1747, y se remitió a la Rl Acad ${ }^{a}$ de la Historia, quien me encargó su interpretación. Sus caracteres de puro adornados, parecian un bordado de capricho, más bien q. letras o geroglificos. Sin embargo tuve la fortuna de leer el $1^{\circ}$ renglón, y la $1^{a}$ palabra del $2^{\circ}$, aunq. confieso debi este acierto a la casualidad de haber visto antes algunas monedas árabes, cuyos caracteres son substanclmte. del mismo sistema de escritura que los de esa inscripción, $p^{o}$ sin adorno alguno. Yo la hubiera leido toda, á no ser tan principiante en la Lengua Arábiga. Lo executó por mi el Sr. Dn. Miguel Casiri, mi maestro en aquel idioma, y sumamte. hábil en él, y en el Siríaco y Caldeo».

41. El proyecto de Academia de Luzán está estudiado en ROCA LÓPEZ, P: op. cit., pp. 845-940. En las páginas finales se encuentra la transcripción completa del mismo.

42. Roca LóPEZ, P.: op. cit., p. 940.

43. Gil FernándeZ, L.: «Campomanes, helenista» en MAteo Dorado, D. (ed.): Campomanes doscientos años después, Oviedo, 2003, p. 16. 
Carbonel Borja quien, pese a ser por entonces muy niño aún, más de medio siglo después todavía guardaba un vívido recuerdo del desarrollo de las mismas y las evocaba del siguiente modo en una carta:

Estando en Madrid D. Luis de Velázquez, concurría a una tertulia de varios literatos, y entre ellos mi padre, que me llevaba siempre consigo. Hablaba Velázquez de sus descubrimientos y lecciones de los caracteres desconocidos de las medallas de España; unas veces le alababan, pero otras se le burlaban, y daban muchas carcajadas de risa; yo como muchacho de unos diez años, hacía lo que veía executar a los concurrentes... ${ }^{44}$

Estas tertulias eran con toda probabilidad las reuniones de la Academia del Buen Gusto que tenían lugar en el palacio de la condesa de Lemos, luego marquesa de Sarriá, y de la que formaban parte el ya citado Luis José Velázquez, futuro marqués de Valdeflores, el conde de Torrepalma y Agustín Montiano y Luyando, director de la Academia de la Historia ${ }^{45}$.

Otro de los amigos de entonces fue el erudito Cándido María Trigueros a quien tanto los Carbonel, padre e hijo, como Campomanes conocieron cuando apenas contaba con quince años de edad y empezaba a despuntar su talento para la poesía. La noticia del fortuito encuentro a raíz del cual surgió la amistad entre todos ellos ha llegado hasta nosotros gracias al relato efectuado por el académico sevillano y gran amigo de Trigueros, Juan Nepomuceno González de León, en carta dirigida a fray Rafael Rodríguez Mohedano:

Este mismo año [1751] y parte del siguiente concurrían a pasearse en la parte del Nuevo Palacio que llaman Jardín de la Priora, don Joseph Carbonel, hoi maestro de los Cavalleros Guardias Marinas, y un hijo suyo, con el Señor Don Pedro Rodríguez Campomanes, entonces Abogado de los Reales Consejos; la uniformidad de la edad hizo que tomase amistad con el joven Carbonel, y su erudito Padre, para que fuese esta amistad útil, les hizo convenirse en que se enseñasen mutuamente, D. Cándido al Carbonel la Prosodia latina, y el Carbonel a D. Cándido la lengua francesa. ${ }^{46}$

44. Contestación de Antonio Carbonel Borja a Luis Carlos de Zúñiga en Efemérides de España, domingo 5 de agosto de $1804, n^{\circ} 218$, p. 890. Carbonel y Zúñiga mantuvieron en las páginas del referido diario una controversia sobre numismática a la que nos referiremos más adelante.

45. El literato malagueño Luis José Velázquez (Málaga, 1722-† id., 1772) se estableció en Madrid a partir de 1748 y fue uno de los miembros de la Academia del Buen Gusto durante el tiempo de existencia de la misma (enero, 1749-septiembre, 1751). La época en que desarrolló sus actividades literarias la citada Academia coincide con los diez años de edad que por entonces tenía Antonio Carbonel Borja quien, como dejamos apuntado más arriba, debió nacer con posterioridad a 1738. Ver CANTO DE GREGORIO, A.: «Un precursor hispano del CIL [Corpus Inscriptionum Latinarum] en el siglo XVIII: el marqués de Valdeflores», en Boletín de la Real Academia de la Historia 191, (septiembre-diciembre 1994) pp. 499516. Un novedoso y reciente esbozo biográfico de Valdeflores se encuentra en ABASCAL PALAZÓN, J. M.; Die Maculet, R. y CeBrián Fernández, R.: Antonio Valcárcel Pío de Saboya, conde de Lumiares (1748-1808). Apuntes biográficos y escritos inéditos, Madrid-Alicante, 2009, especialmente pp. 32-50.

46. Juan Nepomuceno González de León a fray Rafael Rodríguez Mohedano, Sevilla 28-1-1775. La carta se conserva en la Biblioteca Capitular y Colombina de Sevilla (82-4-18). Cfr. AgUiLAR PIÑAL, F.: El académico Cándido María Trigueros (1736-1798), p. 221 y ss. 
El aprecio de Trigueros por sus viejos amigos se mantuvo a lo largo de los años. En 1783, redactó unos «Apuntamientos para el Señor Cavanilles» que debían servir a éste último para contestar el famoso artículo de Masson de Morvilliers aparecido el año anterior en la Encyclopédie Méthodique sobre la decadencia de España. Al hablar de las Humanidades, Trigueros comentaba «Ni falta en España la erudición en otras lenguas antiguas. Es bien notoria, aun a los extranjeros la de los Señores Casiri, Carbonell, Campomanes y otros $\rangle^{47}$. Y años después, siendo bibliotecario de los Reales Estudios de San Isidro, conseguiría el nombramiento como ayudante de su antiguo compañero, Antonio Carbonel Borja, a la sazón bibliotecario del Seminario de Nobles y quien, a la muerte de Trigueros, sería el encargado de redactar el inventario de su biblioteca ${ }^{48}$. A la trayectoria de dicho Carbonel tendremos ocasión de referirnos más adelante.

\section{MAESTRO DE GUARDIAS MARINAS}

Pero en 1752 la vida de José Carbonel iba a experimentar un giro radical. El cambio vendría de la mano del prestigioso marino y científico Jorge Juan Santacilia ${ }^{49}$, figura clave para llevar a buen puerto el ambicioso plan de renovación tecnológica con el que el marqués de la Ensenada pretendía incrementar el poderío naval español. Juan acababa de ser nombrado comandante de la Compañía de Guardias Marinas de Cádiz, y aunque diversos encargos y comisiones le habían retenido en Madrid durante la mayor parte del año 1752, todo ello no le había impedido ultimar un proyecto de reorganización de la Compañía que contemplaba una reforma en los planes de estudio de su Academia y un incremento del nivel de conocimientos exigido a sus profesores ${ }^{50}$. El marino consideraba fundamental mejorar la preparación de los alumnos mediante una formación de carácter científico por lo que reclutó como maestros de la Academia de Guardias Marinas a aquellos individuos que por sus conocimientos matemáticos juzgaba más idóneos para cumplir su cometido, no dudando en despedir a los antiguos profesores que no reunían los requisitos que, a su juicio, eran indispensables. El dominio de varias lenguas y la vasta erudición tanto científica como humanística de José Carbonel le convertían, a los ojos del marino, en la persona más capacitada para ocupar el puesto de maestro

47. Aguilar PiÑal, F.: op. cit., pp. 57-63: «Apuntamientos para el Señor Cavanilles». La cita en p. 60. Un excelente estudio de la apología de España de Cavanilles en MESTRE SANCHIS, A.: Apología y crítica de España en el siglo XVIII, Madrid, 2003, pp. 209 y ss.

48. Simón DíAZ, J.: Historia del Colegio Imperial de Madrid. (Del Estudio de la Villa al Instituto de San Isidro: Años 1346-1955), Madrid, 1992, p. 358. AgUILAR PIÑAL, F.: La biblioteca y el monetario del académico Cándido María Trigueros (1798), Sevilla, 1999, p. 52.

49. Sobre la vida, viajes, aportaciones científicas y trayectoria personal de Jorge Juan (Novelda [Alicante], 1713-† Madrid, 1773) ver GuILLÉn TATO, J. F.: Los Tenientes de Navio Jorge Juan y Santacilia y Antonio de Ulloa y de la Torre Guiral y la medición del Meridiano, Madrid, 1936, 278 pp.; LAFUENTE, A. y MAZUECOS, A.: Los caballeros del punto fijo. Ciencia, politica y aventura en la expedición geodésica hispanofrancesa al virreinato del Perú en el siglo XVIII, Barcelona, 1987, 256 pp.; y DIE MACULET, R. y ALBEROLA ROMÁ, A.: La Herencia de Jorge Juan. Muerte, disputas sucesorias y legado intelectual, Alicante, 2002, 281 pp.

50. La labor desplegada por Juan al frente de la Compañía de Guardias Marinas y su Academia en LAFUENTE, A. y SELlÉs, M.: El Observatorio de Cádiz (1753-1831), Madrid, 1988, pp. 83 y ss. 
de idiomas de ahí que, para conseguir que aceptara trasladarse a la Academia de Cádiz, no dudó en ofrecerle una serie de ventajas con respecto a su puesto en la Casa de Pajes. Estas ventajas, que nunca llegarían a materializarse, las resumiría así muchos años después el propio Carbonel en su ya citada instancia solicitando la jubilación:

...quando se le sacó de la Casa Real para esta Academia, se le prometió, a más de darle alojamiento y considerarle al igual de los Maestros de Matemáticas (supuesto que manda la Ordenanza que las sepa el de Ydiomas estrangeros para poder hacer las traducciones necesarias) que se le graduaría luego que manifestase ser cierto lo que aseguraba el expresado D. Jorge Juan, en su propuesta de 19 de Agosto de 1752 (cuyo original existe en el Archivo de la Secretaría del Despacho Universal de Marina). ${ }^{51}$

Efectivamente, los motivos por los que Juan proponía a Carbonel como maestro y que éste reproduce casi literalmente en su instancia, se encuentran en la carta que el marino dirigió en agosto al marqués de la Ensenada y en la que le comunicaba los nombres de los individuos que consideraba más capacitados para impartir las diferentes asignaturas, refiriéndose a Carbonel con estas elogiosas palabras:

Para maestro de idiomas creo aún más que idóneo a don Joseph Carbonel pues a más de hablar el Griego, Latín, Español, Francés, Italiano, y traducir el Inglés, todo perfectamente, está muy adelantado en Matemáticas, de las cuales también ha sido maestro, muy impuesto en la Historia, y con grandes principios de Física moderna, que acompaña con ser muy buen Filósofo. ${ }^{52}$

Las propuestas de Juan serían respaldadas por Ensenada a primeros de octubre de 1752 mediante una Instrucción por la que se concedían a aquél plenos poderes para introducir todas las reformas que juzgara necesarias ${ }^{53}$. Carbonel debió conocer «oficiosamente» la aprobación de su nombramiento como maestro de idiomas casi de inmediato, y la transmitió rápidamente a sus amigos por lo que, antes de quince días, Campomanes ya incluía en una de sus cartas a Felipe Samaniego, que se encontraba en Italia, una postdata en la que le comunicaba que «el amigo Carbonel va a Cádiz por uno de los maestros de la Academia de los Guardias marinas y estima mucho su expresión de Vuestra Merced ${ }^{54}$. Sin embargo, el nombramiento oficial de José Carbonel

51. AGMAB, Intendencia, leg. 3268/48: Expediente personal de José Carbonel Fogasa, instancia fechada en Isla de León el 2 de junio de 1785 solicitando al Rey la jubilación. Como puede verse en la tabla elaborada por LAFUENTE, A. y SELLÉS, M.: op. cit., p. 96, el sueldo anual de Carbonel en esa fecha (12.000 reales de vellón) era igual al de los restantes profesores y sólo superado por el del director y el del segundo maestro de matemáticas pero según las declaraciones de Carbonel contenidas en la citada instancia, a las que nos referiremos más adelante, con el paso de los años su sueldo permaneció por debajo de los referidos maestros y no se le llegó a graduar.

52. AGS, Marina, leg. 95, Jorge Juan Santacilia al marqués de la Ensenada, Madrid 19-8-1752. Cfr. LAFUENTE, A. y SELlÉS, M.: op. cit., pp. 93.

53. AGS, Marina, leg. 130, Instrucción de 2-10-1752.

54. Pedro Rodríguez Campomanes a Felipe Samaniego, Madrid 14-10-1752. FUE, APC, 23-18. La carta está publicada en AvilÉS, M. y CEJUdO, J. (eds.): Pedro Rodríguez de Campomanes. Epistolario. Tomo I (1747-1777), Madrid, 1983, pp. 29-30. 
como maestro de lenguas de la Academia no se produciría hasta el 14 de octubre de $1753^{55} \mathrm{y}$, para entonces, hacía ya un año que se encontraba residiendo en Cádiz.

Su nuevo destino suponía el alejamiento de Madrid y del ambiente cultural en el que se desenvolvía desde hacía una década. Pese a todo, Cádiz no era un páramo intelectual. La ciudad bullía de actividad gracias al comercio con ultramar y al hecho de ser cabeza de Departamento marítimo y Capitanía General de la Armada. El crecimiento demográfico, económico y militar de su puerto había determinado el establecimiento de importantes instituciones navales, como la Academia de Guardias Marinas, el Hospital Real y el Colegio de Cirugía de la Armada. Estos centros congregaron a su alrededor un elenco de renombrados profesionales -médicos, cirujanos, ingenieros y marinos- que convirtieron a Cádiz en un importante foco de actividad científica.

Una de las primeras tareas de José Carbonel tras su llegada a Cádiz, al margen de sus obligaciones docentes en la Academia, fue la de colaborar con Jorge Juan y Louis Godin en la redacción de los Estatutos de una Sociedad Real de Ciencias de Madrid, propiciada por Ensenada y cuyo objetivo había de ser la enseñanza y difusión de las ciencias físicas y matemáticas. Este proyecto, para el que se había enviado al extranjero al boticario Joseph Ortega, como comisionado para recabar informes y noticias sobre los individuos más relevantes que podrían ser nombrados miembros de aquella, quedó frustrado con la caída del marqués en 1754 dando al traste al mismo tiempo con las aspiraciones del propio Carbonel a quien, al parecer, se le destinaba la Secretaría de la mencionada Sociedad ${ }^{56}$.

Precisamente en relación con el viaje de Ortega, efectuado entre 1752 y primera mitad de 1753, se conserva una carta de Carbonel a Campomanes, sin fecha pero escrita pocos días después de regresar aquél de su comisión ${ }^{57}$. A través de este documento podemos hacernos una idea del carácter ilustrado y utilitarista que animaba a Carbonel:

Amigo y señor: Recibo la de Vm de 22 del corriente en que veo gustoso los sanos pensamientos con que vuelve de su peregrinación don José Ortega. Aunque los españoles no

55. LAFUente, A. y Sellés, M.: op. cit., p. 96. Carbonel, a partir de 1762, sería también bibliotecario de la Academia.

56. Así se desprende de la anotación manuscrita que figura en el encabezamiento de dichos Estatutos: Ordenanzas de S.M. para la Sociedad Real de Ciencias» y al margen «proyectada en 1752 por Dn. Jorge Juan y Dn. Luis Godin, y en cuyo plan trabaxó también Dn. Joseph Carbonel y Fogassa, á quien se destinaba la Secretaría. Por su parte, la cubierta exterior lleva como título: Plan de 50 Ordenanzas para la Sociedad Real de Ciencias de Madrid, por los Sres. Dn. Jorge Juan, Dn. Luis Godin y Dn. Joseph Carbonel y Fogasa. En Cádiz, año de 1753. Cfr. en RocA LóPEZ, P.: op. cit., p. 874. Este autor reproduce el texto íntegro de las referidas Ordenanzas en pp. 903-913. También trascribe en p. 881, n. I, parte de una carta de Antonio Carbonel Borja, escrita hacia 1795, en la que éste alude asimismo al cargo de secretario de la citada Sociedad de Ciencias, prometido años atrás a su padre: «Cuarenta años há (...) que intentó el Ministerio establecer la Academia de Ciencias, nombrando por su Secretario a mi padre, Dn. José Carbonel; pero no había llegado entonces el tiempo prefijado por la Divina Providencia...».

57. Ortega llegó a Madrid, tras finalizar su viaje por varios países europeos, el 12 de mayo de 1753, según manifiesta el botánico sueco Pehr Löfling a su maestro Carl Linné en carta desde Madrid de 14 de mayo de 1753. Cfr. en Asso, I.: «Observaciones de Historia Natural hechas en España y en América por Pedro Loefling», en Anales de Ciencias Naturales, mes de junio de 1802, n 13, tomo V, p. 92. 
sacasen otra cosa de los viajes que el desimpresionarse y trocar sus quimeras en ideas ordenadas al orden y bien universal, se debieran enviar continuamente fuera del Reino, siquiera las cabezas de partido o de todas las clases de ciudadanos. Éstos las derraman y lo bueno se propaga así como lo malo. Son epidemias las ideas así como las enfermedades: la idolatría, las guerras civiles, los duelos, las pruebas judiciarias, las Cruzadas, las romerías, las órdenes militares y..., las brujerías, la caballería andante, las herejías, las Repúblicas, qué se yo, treinta mil manías epidémicas que se van sucediendo continuamente una a otra. Eso es inseparable del hombre, y el ministro que lo sabe aprovecha ese defecto con introducir él mismo por las vías más naturales las semillas de ideas que más conveniente le parecen, para la felicidad del Estado. Así, los ingleses injertan las viruelas benignas para precaver la introducción de las malas..$^{58}$

Carbonel proseguía su carta dando la enhorabuena a Campomanes por haber concluido la traducción del Periplo de Hannon, solicitándole información sobre determinados términos árabes y aconsejándole cultivar la amistad con Louis Godin, a quien describe como un individuo «tan universal en la erudición como en las matemáticas». Uno de sus últimos comentarios nos da idea del vertiginoso ritmo de vida gaditano en el que Carbonel, recién instalado en la metrópoli, se hallaba inmerso: «Las diez de la noche están dando, aquí vivo aún más deprisa que en Madrid».

Pocos meses después llegaría a Cádiz el protagonista de uno de los más importantes viajes ilustrados por España; nos referimos al literato y académico de la Historia Luis José Velázquez, futuro marqués de Valdeflores, quien en 1752 había sido comisionado por dicha Real Academia para recorrer Extremadura y Andalucía recogiendo todos los testimonios y antigüedades referentes a la historia civil de España ${ }^{59}$. Desde el comienzo de su viaje, Velázquez estuvo en contacto epistolar con Agustín de Montiano y Luyando, director de la Academia, a quien mantuvo puntualmente informado del desarrollo de su cometido ${ }^{60}$. A mediados de mayo de 1754 el literato arribó a Cádiz, procedente del Puerto de Santa María, y ya en su primera carta desde esta ciudad se queja a Montiano de la confusión y bullicio que reinaba en las calles impidiéndole el sosiego incluso dentro de la posada. Y también él, como Carbonel, acusa el cambio de ritmo: «Aquí son los dias más cortos que en Madrid y estoi deseando salir de Cádiz,

58. José Carbonel a Pedro Rodríguez Campomanes, Cádiz, s/f. en FUE, APC, 37-27-1; reproducida en Herrera Navarro, J. (ed.): Pedro Rodríguez de Campomanes. Epistolario (1778-1802), Madrid, 2004, vol. II, carta $n^{\circ} 613$, pp. 609-610.

59. El padre Andrés Burriel y Francisco Pérez Bayer fueron los encargados de recoger los documentos de la historia eclesiástica. Velázquez principió su comisión el primero de diciembre de 1752 visitando parte de Castilla la Nueva, Extremadura y parte del reino de León hasta Salamanca. En septiembre de 1753 entró en Andalucía recorriéndola en su mayor parte y concluyendo el 31 de diciembre de 1754. Hasta ese momento contó con financiación oficial pese a que la caída en desgracia del marqués de la Ensenada, producida meses antes, determinó la suspensión del proyecto. Pero decidido a concluir su labor aunque fuera a sus expensas, a partir de 1755 y hasta finales de 1760 Velázquez realizó cuatro viajes complementarios por Andalucía, Ceuta, La Mancha y parte de Castilla la Nueva, ya sin financiación oficial pero con consentimiento de la Academia. Ver Abascal Palazón, J. M.; Die Maculet, R. y Cebrián FERNÁNDEZ, R.: op. cit., pp. 32 y ss.

60. El epistolario de Velázquez a Montiano se conserva en la Biblioteca Nacional, Mss. 17.546. 
para poder pensar $\rangle^{61}$. Pese a todo, en las pocas jornadas transcurridas desde su llegada ya había entrado en contacto con las personas que mejor podían ilustrarle para llevar a cabo su labor, es decir, el marqués de la Cañada, Juan Tirry, poseedor de un importante gabinete de antigüedades; el director de la Academia de Guardias Marinas, Louis Godin, "que es un sabio hecho y derecho. Siendo tan gran matemático, es hombre de buenas letras, $y$ de un gusto mui singular en todo» ${ }^{62} \mathrm{y}$, naturalmente, su viejo compañero de tertulias y académico como él, José Carbonel, de quien comenta a Montiano:

Carbonell tiene trabajadas ciertas disertaciones sobre la lengua Hebrea y Arábiga que son muy doctas; i cuando las publique se justificará mi sentir acerca de sus talentos y aquellos Señores verán lo que desatendieron. ${ }^{63}$

Desconocemos la identidad de los «Señores» a los que alude Velázquez y cuál fue la desatención tenida en el pasado hacia Carbonel, aunque para Rueda Muñoz las palabras del literato apuntan a ciertas reticencias existentes en el seno de la Academia de la Historia cuando se admitió en ella a Carbonel como miembro honorario ${ }^{64}$.

Pocos días después, Velázquez abandonó Cádiz para continuar su recorrido por Andalucía sin imaginar que, en menos de dos meses, la caída del marqués de la Ensenada a finales del mes de julio ${ }^{65}$, iba a conllevar la suspensión definitiva del proyecto en el que se hallaba embarcado y la retirada de la pensión mensual que tenía asignada para realizar su comisión. Pese a todo, y como ya dijimos anteriormente, a partir de 1755 sería el propio Velázquez quien correría con los gastos, decidido a concluir su periplo por las provincias andaluzas y que no se perdiera el fruto de tanto esfuerzo. Pero el literato malagueño no fue el único que sufrió los efectos políticos del cese del ministro. Los cambios en la Secretaría de Marina, con su nuevo titular Julián de Arriaga al frente de la misma, determinaron la paulatina pérdida de influencia de Jorge Juan Santacilia, otro protegido de Ensenada y uno de sus principales consejeros, quien se vio relegado del círculo de toma de decisiones y contempló cómo quedaban paralizados muchos de sus proyectos, entre otros el levantamiento de un Mapa de España con arreglo a las más modernas técnicas geodésicas y cartográficas, así como la creación en Madrid de una Sociedad Real de Ciencias, a la que ya nos hemos referido páginas atrás.

61. Luis José Velázquez a Agustín Montiano, Cádiz 14 de mayo de 1754, en BN, Mss. 17.546, ff. 176-176vº 62. Ibidem.

63. Ibidem. El trabajo de Carbonel al que se refiere Velázquez podría tratarse de la disertación titulada De la utilidad de las lenguas originales y en particular de la Arábiga $p^{a}$ la Hist ${ }^{a}$ y Geog ${ }^{a}$ de España, con unas prenociones de su idioma, escritura y Literatura, por Dn. Joseph Carbonel Fogasa y Bonfigli, 1753. (BN, Mss. 11552, Papeles varios, h. 74-93v).

64. RUEDA MUÑOZ, G.: op. cit., p. 228.

65. El Real Decreto por el que se deponía a Ensenada de todos sus empleos y se le desterraba a Granada se publicó en la Gazeta de Madrid del 23 de julio de 1754. 


\section{LA «ASAMBLEA AMISTOSA LITERARIA» DE CÁDIZ}

Juan asumió con estoica resignación el cambio de rumbo del Ministerio, "se han trocado los bolos -escribiría meses después al secretario de Ensenada- y hallo que no hay cosa como estarse en su rincón ${ }^{66}$. Y así, dedicado en cuerpo y alma a la dirección de la Compañía de Guardias Marinas y a sus trabajos científicos, a principios de 1755 estableció una tertulia que denominó Asamblea Amistosa Literaria cuyas reuniones se celebraban todos los jueves en su residencia gaditana y en las que sus miembros exponían memorias y disertaciones de toda índole. Presidida por Jorge Juan, concurrían a ella profesores de la Academia de Guardias Marinas como el director Louis Godin, los maestros de matemáticas José de Aranda y Gerardo Henay, y el maestro de artillería José Díaz Infante; miembros del Real Colegio de Cirugía de la Armada con su director, Pedro Virgili, al frente, Francisco Canivell, Lorenzo Roland y Francisco Nueve-iglesias, y médicos como Diego Porcell y José de Nájera. Como secretario de dicha Asamblea actuaba José Carbonel ${ }^{67}$.

Conocemos el espléndido ritmo de las actividades que se realizaban en el seno de esta Asamblea gracias a la ya citada carta de Jorge Juan a Antonio Roselló, capellánsecretario del marqués de la Ensenada:

También quedo muy contento de tener su aprobación en cuanto a nuestra recién nacida Asamblea, que tira adelante bonitamente, y esto aún con todos los trabajos a que tienen que atender sus individuos (...) Con todas estas dificultades no nos falta que leer todos los jueves cosa nueva, sea de unos, sea de otros; y espero que en todo el año podremos dar a la imprenta un tomo de 30 o de 40 disertaciones, si hallamos modo de hacer el coste. ${ }^{68}$

A mediados de octubre de 1755, Luis José Velázquez pasó nuevamente por Cádiz a su regreso de un viaje a Ceuta realizado para completar la recogida de antigüedades y monumentos que desde principios de año efectuaba ya a su costa. A través de Carbonel conoció la creación de la Asamblea Amistosa de la que quedó agradablemente sorprendido como así se refleja en su correspondencia con Montiano:

En Cádiz he encontrado con harta satisfacción mía una Junta de Literatos de primer orden establecida en forma de Academia, donde se cultivan no sólo las Matemáticas, y las Sciencias exactas, sino las buenas letras. Este establecimiento podrá algún día ser de algún honor, y utilidad á la Nación. Carbonel es el secretario de esta Junta. ${ }^{69}$

Aunque la estancia de Velázquez en Cádiz no fue larga, pudo prolongarse lo suficiente como para permitirle asistir a una o dos reuniones de la Asamblea Amistosa

66. Jorge Juan a Antonio Roselló, Cádiz 11 de marzo de 1755. Cfr. en RoCA LÓPEZ, P.: op. cit., pp. 894-895.

67. Sobre la creación y actividades de la Asamblea Amistosa Literaria ver PANDO VilLARROYA, J. L.: op. cit., $255 \mathrm{pp}$.

68. Jorge Juan a Antonio Roselló, Cádiz 11 de marzo de 1755. Cfr. en RoCA LÓPEZ, P.: op. cit., pp. 894-895.

69. Luis José Velázquez a Agustín Montiano, Málaga 28 de octubre de 1755, en BN, Mss. 17.546, ff. 281282. 
Literaria las cuales, como queda dicho, se celebraban los jueves ${ }^{70}$. Nada dice en sus cartas respecto a que en esa primera toma de contacto fuera admitido como miembro de la misma, por lo que su incorporación hubo de producirse con posterioridad. Él mismo confirma su pertenencia a dicha sociedad en su obra Noticia del Viage de España ${ }^{71}$ donde, al comentar las empresas literarias iniciadas bajo el reinado de Fernando VI, menciona la Asamblea gaditana, de la que indica:

Las primeras Juntas se tubieron en Cádiz; y de los Académicos que concurrieron a ellas con sus trabajos, fueron D. Jorge Juan, D. Antonio de Ullóa, y Mr. Godin en las Matemáticas; el Dr. Porzell en la Medicina; D. Pedro Virgilio en la Cirugía; D. Josef Carbonél en las Lenguas Orientales, y buenas Letras; y el Autor de este Viage en la Historia y las Antigüedades. ${ }^{72}$

Las cartas de Velázquez a Montiano nos ofrecen, además, una curiosa noticia protagonizada en parte por Carbonel al ser éste el Cicerone del literato malagueño durante los días que permaneció en Cádiz. Velázquez, al parecer, tenía noticias de que había llegado al puerto gaditano un nieto del gran dramaturgo francés Racine e hijo del poeta y académico Louis Racine con quien mantenía una amistosa correspondencia. En un principio se esperaba que el joven, que iniciaba una prometedora carrera como comerciante de vinos, desembarcara en Málaga pero finalmente lo hizo en Cádiz, circunstancia que Velázquez decidió aprovechar para visitarle y ponerse a su disposición en todo aquello que necesitara. En compañía de José Carbonel se dirigió a la casa donde se alojaba pero no lograron verle por encontrarse ausente:

En Cádiz supe que ya estaba allí el hijo de Mr. Racine; fui con Carbonel a buscarlo, para ofrecerme a lo que quisiese mandarme; y nos dixeron en su casa cómo estaba en una Quinta de la Isla; con que me fue forzoso venirme sin verle. ${ }^{73}$

Ya no se le presentaría otra oportunidad de cumplimentar al joven comerciante pues Velázquez regresó a Málaga el 19 de octubre y, pocos días después, el 1 de

70. No podemos precisar con exactitud los días que Velázquez pasó en Cádiz a su vuelta de Ceuta. Por las fechas de sus cartas a Montiano, vemos que viajó a Ceuta después del 9 de septiembre de 1755, día en que todavía se encuentra en Málaga. El 19 de octubre de ese año, escribe ya desde Cádiz comunicando haber retornado de Ceuta días atrás y que a la mañana siguiente emprendería viaje de vuelta a Málaga.

71. VelázQuez de Velasco, L. J.: Noticia del Viage de España hecho de orden del Rey. Y de una Nueva Historia General de la Nación desde el tiempo más remoto hasta el año 1516. Sacada únicamente de los Escritores y Monumentos originales, y contemporáneos. Con la colección universal de estos mismos Escritores, y Monumentos recogidos en este Viage. Por D.---, Marqués y Señor de Valdeflores, Señor de Sierra blanca, Caballero de la Orden de Santiago. En Madrid, en la oficina de D. Gabriel Ramírez, año de 1765 .

72. VelázQuez De Velasco, L. J.: op. cit., p. 7, nota 7. Efectivamente, el manuscrito titulado Memorias leídas en la Asamblea Amistosa Literaria de Cádiz, que se conserva en BN, Mss. 11553; contiene varias disertaciones de Godin, Virgili, Díaz Infante, Porcell, Canivell, Tofiño y el propio Carbonel, así como tres comunicaciones que Velázquez remitió a Carbonel en 1758 (pp. 248 a 309) para ser incluidas en el volumen que éste preparaba para la imprenta y que nunca llegó a publicarse.

73. Luis José Velázquez a Agustín Montiano, Málaga 4 de noviembre de 1755, en BN, Mss. 17.546, ff. 283284. 
noviembre de 1755, se produjo el terrible terremoto que destruyó Lisboa, asoló el sur de Portugal y causó tremendos estragos en la Andalucía occidental. En Málaga los daños fueron de muy escasa entidad pero Cádiz resultó gravemente afectada al ser alcanzada, tras el seísmo, por un maremoto que provocó la muerte de unas treinta personas que huían por la carretera del istmo que llevaba a la isla de León y entre las que se encontraban el joven Racine y su socio y amigo Joseph Juan Mason ${ }^{74}$.

Cabe suponer que Carbonel fue testigo directo de la catástrofe y que, a buen seguro, debió dar cumplida referencia de ella a alguno de sus corresponsales pero, lamentablemente, no ha llegado hasta nosotros ningún escrito suyo en ese sentido. Lo que sí sabemos es que, a los pocos días del terremoto, leyó ante la Asamblea Amistosa una disertación de tema arqueológico titulada De algunas antigüedades encontradas debaxo de tierra en el Ystmo de Cádiz; y pocos meses después otra, sobre agricultura, cuyo título era Sobre el modo de fecundizar el terreno del Ystmo de Cádiz ${ }^{75}$.

Es evidente que escribir dichas disertaciones y llevar la Secretaría de la Asamblea le suponía a Carbonel un esfuerzo añadido a las, ya de por sí, exigentes tareas como maestro en la Academia de Guardias Marinas. Y como muestra basta con leer la relación de obligaciones que él mismo expone en su ya citada instancia de 1785 y entre las cuales estaba, no sólo la enseñanza de idiomas, sino también la traducción de tratados de Matemáticas, Artillería o Navegación para el uso de los alumnos ${ }^{76}$, así como la de todos los impresos o manuscritos franceses, italianos, ingleses y latinos que le encargaban los generales y oficiales del Departamento de Cádiz. Por añadidura, muchos de los profesores y miembros de la Asamblea solían recurrir a él para que revisara la redacción y la ortografía de los libros y disertaciones que estaban a punto de ser publi$\operatorname{cados}^{77}$. Además de todo lo expuesto, enumeraba Carbonel en su instancia que:

Fuera de estas tareas propias de su empleo, ha corregido, en la Ortografía, explicación y estilo, el tratado de Navegación de su difunto capitán Dn. Jorge Juan, la Aritmética del antepenúltimo Director Dn. Luis Godin, la Artillería del Maestro de ella Dn. Jph. Díaz Ynfante, la Maniobra de Dn. Santiago Zuloaga, la Artillería de Dn. Francisco Rovira, y

74. Así lo indica Luis Godin en el informe que se le mandó hacer titulado Sobre el Temblor de Tierra que se sintió en Cádiz el día $1^{\circ}$ de Noviembre de 1755. Cfr. MARTíneZ SOLARES, J. M.: Los efectos en España del terremoto de Lisboa (1 de noviembre de 1755), Madrid, 2001, p. 227.

75. BN, Mss. 11.553, Memorias leídas..., pp. 119-139v․ La primera disertación lleva fecha del 27 de noviembre de 1755 y ha sido estudiada y transcrita por RUEDA MUÑOZ DE SAN PEDRO, G.: op. cit., pp. 227-235. La segunda comunicación fue leída ante la Asamblea el 11 de marzo de 1756.

76. En el libro Ynventario de todos los Muebles, Instrumentos, Máquinas y Libros que pertenecen a la Academia de Guardias Marinas de Cádiz que se custodia en el Archivo Histórico del Real Observatorio de la Armada de San Fernando, Cádiz (AHROA), 1.081-AH, se incluye la obra Reglas del Diseño para lavar los Planos de fortificación y Arquitectura Civil, \& traducido del francés por el Comisario de Marina y Académico supernumerario de la Historia de Madrid Dn. Joseph Carvonel y Fogasa siendo maestro de Ydiomas estrangeros en la de Guardias Marinas para el uso de la misma. Manuscrito sin encuadernar.

77. En BN, Mss. 11.553, Memorias leidas..., pp. 73 y 237 se conservan dos notas de José Díaz Infante y una de Pedro Virgili, rogando a Carbonel la revisión y corrección de sus trabajos. 
finalmente la Geometría que al presente se enseña en la Academia (...). Ha rehecho también enteramente en la explicación el tratado de Artillería de Dn. Sebastián Labairu, Maestro principal que fue de las Brigadas de Marina, y el de Bendages del Real Colegio de Cirujanos de Cádiz (...). Finalmente, todo el tiempo que duró, en la Academia de Guardias Marinas de Cádiz, la Asamblea Literaria, fue el Suplicante Secretario de ella, trabaxando, en los intervalos libres de sus ocupaciones esenciales, en llevar el Registro, extractar las varias disertaciones que escribían sus Yndividuos, especialmente Dn. Pedro Virgilio y Dn. Diego Purcel; y componer algunas por sí sobre puntos útiles de Erudición e Historia Natural. ${ }^{78}$

Sin embargo, pese a toda la dedicación y esfuerzo empleados por Carbonel en el desempeño de su cargo como secretario y miembro de la Asamblea gaditana, la vida de ésta no se prolongó más allá de dos o tres años. Inicialmente, la suspensión de las reuniones se debió a la marcha de Louis Godin a París ${ }^{79}$ y a las múltiples obligaciones que encontró a su regreso, siendo la principal de ellas, la redacción de un tratado de matemáticas para uso de la Academia de Guardias Marinas ${ }^{80}$. Así se desprende de la extensa carta que en 1757 dirigió Carbonel al ingeniero francés Charles Le Maur en la que, entre otros asuntos, le describía la creación y actividades desarrolladas por la Asamblea Amistosa y la interrupción de sus reuniones desde hacía más de un año, lamentando que por ese motivo no hubiera sido posible dar a la imprenta un volumen en cuarto con las disertaciones presentadas por los miembros:

Nous avons formé en effet dans ce païs-ci une petite Acad. sous le titre d'Assemblée Litteraire. Mr. J. Juan en est le President, Mr. Godin le principal membre. J'en suis le Secretaire, et pour la Physique nous avons Dn. Pedro Virgilio, Directeur de notre College R1. de Chirurgie du Marine, les Maitres du meme College et le premier Medecin. Nos Assemblées sont interrompues depuis plus d'un an, à cause du voyage de Mr. Godin á Paris, et des traités pour l'Acad. des Gardes de la Marine, auxquels il travaille depuis son retour. Je ne sais quand elles recommenceront, parce que j'ignore quand ces traités seront finis. C'est dommage: nous avons deja des materiaux pour donner un bon in quarto au public, et il ne s'agissoit plus que du choix des memoires et de leur correction. ${ }^{81}$

Pero no cabe achacar exclusivamente a Godin la muerte de la Asamblea. Tras casi dos años de vigorosa actividad, tanto su presidente como algunos de sus miembros más representativos comenzaron a ausentarse largas temporadas de Cádiz y hubo, incluso, quien marchó de forma definitiva. Así, a partir de 1757, Jorge Juan debió de atender a continuas e importantes comisiones que requerían toda su dedicación, como la de apagar el incendio de las minas de Almadén o reparar la rotura de los diques de carena en Cartagena. De ahí que sus estancias en la urbe gaditana fueran espaciándose cada vez más hasta el punto de que estuvo ausente de la misma durante más de siete años, entre

78. AGMAB, Intendencia, leg. 3268/48: Expediente personal de José Carbonel Fogasa.

79. Godin realizó un viaje a París en 1756 para conseguir recuperar su plaza en la Academia de Ciencias francesa de la que había sido expulsado en 1745. LAFUENTE, A. y SELLÉs, M.: op. cit., pp. 148-151.

80. Godin, L.: Compendio de Mathematicas para el uso de los Cavalleros Guardias-Marinas, por el Coronel Don ----- (...), En Cádiz, en la Imprenta de la misma Academia. MDCCLVIII.

81. José Carbonel a Charles le Maur, Cádiz 7 de septiembre de 1757, en FUE, APC, 48/150. 
comienzos de 1759 y finales de $1766^{82}$. Por su parte, tanto Pedro Virgili como Diego Porcell abandonaron Cádiz en 1758 y marcharon a Madrid, de forma casi simultánea, al ser nombrados médicos de cámara del Rey. Ese mismo año Carbonel escribió dos disertaciones sobre libros y autores árabes ${ }^{83}$ y Velázquez, por su parte, envió las suyas sobre monedas a las que nos hemos referido con anterioridad pero, pese a todo, la actividad normal de la Asamblea fue decayendo paulatinamente hasta su total paralización.

Se frustró, una vez más, la trayectoria de Carbonel como secretario de una Academia de Ciencias, con todo el prestigio que ello habría supuesto para su persona, fracasando asimismo, por falta de medios, la publicación del volumen con las memorias leídas por sus miembros, el cual tambien le habría reportado algún beneficio pues, según comentaba a Le Maur, "ce volume nous auroit attiré la protection du Roy, et il m'en seroit revenue quelque chose de plus que de l'honneur; tout est au croc». Y aunque la decepción y el desaliento eran grandes ante la inutilidad de tanto esfuerzo derrochado - «J'ai travaillé comme un forçat»-, todo ello no dejaba de tener su contrapartida pues, al menos, «j'y ai gagné la facilité d'écrire, d'extraire, d'agir et de parler en public: ce qui peut avoir des suites $\rangle^{84}$.

Interesa señalar que la carta de Carbonel no se reducía a comentar los avatares de la Asamblea Amistosa Literaria, sino que tenía un propósito bien definido cual era el de recurrir a la influencia que Le Maur, su viejo amigo y antiguo compatriota, pudiera tener ante las instancias superiores para lograr con su intermediación una mejora de su situación profesional. La razón de todo ello posiblemente haya que buscarla en el hecho de que habían transcurrido ya cinco años desde que Carbonel aceptara desempeñar el puesto de maestro de idiomas en la Academia de Guardias Marinas, sin que hasta la fecha se hubieran materializado las ofertas hechas en su día respecto a concederle un grado de oficial con el que progresar en el cuerpo general de la Armada, e igualar su sueldo con el de los maestros de matemáticas; pero, también -y así lo reconocía sin ambages Carbonel- por no poder abandonar ese título de «maestro» que ofendía su vanidad. Por ello Carbonel hacía un repaso de su situación ante Le Maur, poniendo de manifiesto sus cualidades personales, sus amplios conocimientos y su experiencia como secretario de una academia científica presidida por Jorge Juan y Louis Godin, subrayando las alabanzas recibidas de este último:

82. LAfuente, A. y SelléS, M.: op. cit., p. 104. El propio marino, en carta a Miguel Múzquiz escrita hacia septiembre de 1766, exponía los deseos que tenía de volver a Cádiz tras la larga ausencia: «Amigo y señor: el Bailío no quiere enviarme sino á Cartagena, el viage a Cádiz yo se lo pedí, con ánimo de ir a visitar mi Compañía aunque no fuese sino por dos meses, por que ha 7 1/2 años que no la veo», en AGS, Marina, leg. 50, correspondencia de Jorge Juan con Miguel Múzquiz sobre construcción de un navío en Génova.

83. Se trata de la Bibliotheca Arábico-Hispana o Catálogo Alphabético de Autores Árabes Españoles $u$ oriundos de España o cuyas obras pertenecen a la Historia y Geographia de ella y del Catálogo de libros árabes, sacados de la Biblioteca de Dn. Nicolás Antonio que pueden conducir para la Historia y Geographia de España. Ambas están escritas en Cádiz en 1758 y se conservan en BN, Mss. 11554, n 45, y Mss. 11552, $\mathrm{n}^{\circ} 46$, respectivamente.

84. José Carbonel a Charles le Maur, Cádiz 7 de septiembre de 1757, en FUE, APC, 48/150. 
Ma situation presente est si avantageuse, que si j'etois officier, comme presque touts mes confreres le sont, et comme j'ai esperance de l'etre un jour, je ne sais pas trop ce qu'on pourroit m'offrir pour me tenter, et quelles suretees il me seroit possible de prendre, egales á celles que j'ai dans mon emploi d'aujourd'hui; tout ce qui me tente actuellement, c'est la compagnie d'un ami tel que vous, de M. Campomanes, etc; les bontés dont m'honnorent tant de Grands, la Cour, l'honneur d'etre officier, l'avantage d'être dans une carrière propre á s'avancer, et enfin le plaisir de quitter ce titre de maitre, qui tout doré qu'il est, ne laisse pas de choquer ma vanité. On est donc encore á tems d'aquerir un homme qui joint les Belles-Lettres aux Langues, à l'erudition et aux Mathematiques, qui sait l'Espagnol, bien au delá de ce qu'ils s'imaginent, qui sait ecrire et qui a deja servi un an dans l'employ de Secretaire d'une Acad.e de Sciences où presidoient un D. J. J. et Mr. G... àvec une telle satisfaction de touts les membres, que ce dernier a dit plusieurs fois, qu'un pareil Secret.e pourroit briller dans quelque Acad.e que ce fut. C'est ici une des ocasions ou on est obligé de dire du bien de soi meme: en tout cas si je peche contre la modestie, je ne manque point à la verité, et cela me suffit auprés de vous. Vous excuserez aisemt. tout autre défaut. ${ }^{85}$

También le informaba de que tres semanas atrás había escrito en similares términos a Pedro Rodríguez Campomanes, por entonces asesor del juzgado de Correos, y a Rudesindo de Tilly, su antiguo camarada de Orán y a la sazón comandante de Artillería de Cádiz, quien le había prometido ayudarle. Finalizaba su carta rogando a Le Maur se interesara por su asunto, no sin antes lamentarse de lo completamente olvidado y desaprovechado que se sentía pese a haber estado siempre tan bien considerado.

Pero nada consiguió Carbonel de los buenos oficios e influencias de sus amistades, si es que alguna vez intentaron mover los hilos a su favor. Pocos años después, hacia 1760, y aprovechando la circunstancia de haber recibido el marqués de Gamoneda cierta distinción, Carbonel le escribió dándole la enhorabuena, explicándole su situación y recordándole la amistad que les había unido en el pasado. Pero, transcurrido cierto tiempo sin haber recibido respuesta, hubo de aceptar resignadamente la ingratitud de su antiguo discípulo y así se lo comentó a Campomanes:

Há de esto 3 o 4 correos y, no habiéndome respondido, temo se verifique en él el axioma de fortuna mutat mores, aunque no siempre el silencio es prueba de olvido, teste te. Yo he cumplido, la ocasión es la más favorable que pudiera desear; si no da fruto lo sembrado no me admiraré, convencido íntimamente del nisi dominus edificaverit domum, in vanum lavoraverunt etc... ${ }^{86}$

En 1762 Carbonel sería nombrado, además, bibliotecario de la Academia de Guardias Marinas pero en los años sucesivos no lograría mejorar su desventajosa situación profesional la cual permanecería invariable hasta que en 1785 solicitara y obtuviera la jubilación; pero a todo ello nos referiremos más adelante.

\section{Ibidem.}

86. La cita latina completa es «Nisi Dominus aedificaverit domum in vanum laboraverunt qui aedificant eam» (Si el Señor no edifica la casa, en vano trabajan los que la construyen). José Carbonel a Pedro Rodríguez Campomanes, s/f s/d, FUE, APC 37-27-2. Cfr. en HERrera NAVARro, J. (ed.): op. cit, pp. 616-617. 


\section{LAS AFICIONES DE CARBONEL: EL GABINETE DE HISTORIA NATURAL Y EL MONETARIO}

Como veremos a continuación, las tareas docentes en la Academia de Guardias Marinas y las relativas a su doble condición de secretario y miembro de la Asamblea Amistosa Literaria no eran las únicas que ocupaban el tiempo del erudito maestro. Carbonel sintió también gran inclinación hacia las Ciencias Naturales y la Numismática, disciplinas que cultivó como mero aficionado pero en las que logró alcanzar un cierto nivel del que nos han quedado interesantes referencias y testimonios.

Las primeras noticias relativas a esta «afición» de Carbonel las encontramos en el epistolario del naturalista sueco Clas Alströmer quien, entre 1760 y 1764, viajó por España y otros paises europeos enviado por su maestro, el botánico Carl Linné ${ }^{87}$. Alströmer llegó a Cádiz el 28 de abril de 1760 tras dos meses de dura navegación en un barco de la Compañía sueca de las Indias Orientales que había zarpado del puerto de Goteborg. En la urbe gaditana entró en contacto con miembros del Colegio de Cirugía y de la escuela de Guardias Marinas, por lo que pronto entabló amistad con José Carbonel. Los datos que sobre este último aporta Alströmer en su correspondencia con Linné ponen de relieve los conocimientos en Ciencias Naturales y la soberbia colección de moluscos y corales que poseía Carbonel, lo cual nos hace suponer que éste debió comenzar a formarla tras su llegada a Cádiz en 1752 y para cuando Alströmer la contempló, ocho años después, era ya de tal calidad que inmediatamente llamó la atención del joven naturalista sueco quien no tardó en comunicarlo a Linné:

Hay aquí un profesor en la Escuela de Guardiamarinas, francés de nacionalidad y de nombre Carbonel, que tiene mucho interés por la Historia Natural y que posee una hermosa colección de conchas, de lithophita y zoophita, no tan ridícula como suelen ser las colecciones por aquí, sino verdaderamente seria y ambiciosa. Él me ha dado bastantes cosas y me ha prometido recoger más para el señor Arquiatra y para mí. Para los señores Grill de Estocolmo ya ha colectado cosas antes. Tiene algunos conocimientos de Botánica, pero quiere saber más y por eso me ha pedido que yo le consiga los siguientes libros del señor Arquiatra: Sistema Naturae ed. alt., Philosoph. Botan., Genera Plant., Biblioteca Botan., Species Plantarum, Amoenitatis academ. El señor Arquiatra se haría un gran favor a sí mismo y se lo haría también al señor Carbonel y a mí, si nos enviase esos libros a la dirección del cónsul Bellman con el primer barco que zarpe. El señor Bellman se encargará de su pago inmediato. Este señor Carbonel es un hombre muy atento y ha procurado hacer por el señor Arquiatra todo lo que ha podido. ${ }^{88}$

87. Linné se propuso clasificar y poner nombre a todos los seres vivos conocidos para lo cual, a partir de 1750, envió a un grupo de alumnos (a los que llamó «apóstoles») a lejanos paises con la misión de descubrir, recoger y catalogar las distintas y desconocidas especies de cada lugar, y así llegar a conocer el cuadro completo de la «creación del mundo». Alströmer (1736-1794) inició su viaje en febrero de 1760 , recalando en Cádiz y visitando posteriormente varios paises de Europa. Regresó a su patria en noviembre de 1764. Todo lo referente a la estancia de Alströmer en Cádiz y a su correspondencia con Linné en FERNÁNDEZ PÉREZ, J.: op. cit., p. 51-102.

88. Clas Alströmer a Carl Linné, Cádiz 10 de junio de 1760, cfr. en FERNÁNDEZ PÉREZ, J.: op. cit., pp. 96-98. Alströmer utiliza el tratamiento de «arquiatra» (médico) para dirigirse a Linné. 
Carbonel, como vemos, aparte de poseer ciertos conocimientos de Botánica, ya había realizado con anterioridad actividades de búsqueda y recolección de especies que enviaba a Suecia a través de la firma comercial Grill ${ }^{89}$ y que estaban destinadas, sin duda, a engrosar las colecciones de museos y aficionados. No se le escapaba a Alströmer la conveniencia de contar con una persona en Cádiz como Carbonel a quien poder recurrir para la obtención de especímenes, aunque para ello era imprescindible que éste poseyera los libros e instrumentos precisos para identificarlos o, al menos, clasificarlos someramente; de ahí que se apresurara a sugerir a Linné el envío de algunas de sus obras como regalo. Pocas semanas después le proponía, además, nombrar a Carbonel su corresponsal:

Como corresponsal para el señor Arquiatra en Cádiz no conozco a mejor persona que al ya citado profesor Carbonel, que es muy atento y buen amigo mío. Se alegraría mucho si el señor Arquiatra a su cuenta o a la mía le regalase los libros que le indiqué. Yo mismo le informaré de esta correspondencia, y cuando el señor Arquiatra le quiera escribir lo puede hacer a la dirección del cónsul J. M. Bellman en Cádiz. (...) Mi investigación respecto al Sanguis draconis arbor ha tenido mala suerte ya que florece en abril y sólo pude ver fruta ya madura. Carbonel ha prometido enviarle flores secas el año que viene al señor Arquiatra.... ${ }^{90}$

En septiembre, Alströmer prosiguió su viaje por Andalucía. En su trayecto coincidió con el botánico José Celestino Mutis, que se disponía a marchar a América, a quien regaló libros y animó a establecer contacto con Linné ${ }^{1}$. De todo ello puso en antecedentes a este último en carta escrita desde Sevilla en la que sugería también a Louis Godin como corresponsal debido, principalmente, a lo ventajoso que podría resultar para Linné contar con tan prestigioso científico, pese a reconocer que era «un poco vago» para escribir cartas y carecía de conocimientos de Historia Natural. Finalizaba su carta confirmando haber encargado a Carbonel la corresponsalía y reiterando nuevamente a Linné le enviara sus libros como regalo ${ }^{92}$.

La breve estancia de Alströmer en Cádiz no tuvo más consecuencia para la Botánica española que el haber puesto en relación a Mutis con Linné, pues las corresponsalías de Carbonel y Godin no dieron el fruto apetecido. Godin moriría pocos días después de escrita la carta anterior y por lo que respecta a Carbonel, su dedicación a las Ciencias Naturales no pasaría nunca de la mera afición aunque, dentro de estos límites, hay que señalar que su gabinete de Historia Natural llegó a gozar de cierta reputación

89. Uno de sus miembros, Clas Grill, era director de la Compañía Sueca de las Indias Orientales, cargo que el propio Alströmer obtendría en 1770.

90. Clas Alströmer a Carl Linné, Sanlúcar de Barrameda 12 de agosto de 1760, cfr. en FERNÁNDEZ PÉREZ, J.: op. cit., p. 99-100.

91. Sobre Mutis ver FríAs NúÑEZ, M.: Tras El Dorado vegetal. José Celestino Mutis y la Real Expedición Botánica del Nuevo Reino de Granada (1783-1808). Sevilla, 1994; PUERTO SARMIENTO, F. J.: La ilusión quebrada. Botánica, sanidad y política científica en la España ilustrada, Madrid, 1988; y AMAYA, J. A.: Celestino Mutis y la Expedición Botánica, Madrid, 1986.

92. Clas Alströmer a Carl Linné, Sevilla 6 de septiembre de 1760, cfr. en FERnÁNDEZ PÉREZ, J.: op. cit., p. 100-101. 
entre eruditos como el padre Flórez, quien lo visitó en mayo de 1768, en el transcurso de un viaje por Andalucía ${ }^{93}$.

Un año antes, la Academia de la Historia también había mostrado su interés por la actividad de Carbonel como naturalista hasta el punto de solicitarle un catálogo sobre la materia que éste rehusó elaborar por falta de conocimientos. Su contestación, sin embargo, resulta de gran interés pues nos permite hacernos una idea de los ejemplares que componían su colección así como de las precarias condiciones en las que desarrollaba sus aficiones. Exponía Carbonel que nunca se había dedicado a la rama de peces, «assi escamosos como cetáceos y blandos», debido a las graves dificultades que suponía su mantenimiento, razón por la que, desde hacía poco tiempo, había abandonado también la de los crustáceos «por no ser favorable a su conservación el aire de esta ciudad y aun menos el de esta casa que me da el Rey». En consecuencia, se había centrado en reunir «testáceos..., corales, madréporas y coralloides», de los que poseía una colección mucho más rica y variada de lo que solía ser habitual en gente más entendida; aun así, el inconveniente que Carbonel encontraba para poder satisfacer la petición de la Academia estribaba en que tan sólo conocía los nombres genéricos de sus especímenes pero no los específicos de cada uno, pues entre los pescadores y gentes de mar se ignoraba la denominación de muchos de ellos o bien ésta variaba de un puerto a otro.

Finalizaba Carbonel su carta evidenciando la falta de medios que padecía y que le impedía satisfacer la petición de la Academia ya que, pese a poseer las obras de Linné -seguramente obtenidas gracias a la mediación de Alströmer- éstas no le eran de gran ayuda para identificar cada especie, al no ir acompañadas las descripciones del naturalista sueco de láminas en las que poder reconocerlas:

Para individualizar las demás especies anonymas, es preciso acudir a la descripción y esta es prolixa, difícil, vaga y quasi siempre inútil para los que no han visto y manejado mucho estas colecciones; y aun para estos sirve de poco sin el auxilio de las laminas. Por falta de estas no puedo entender las mas de las especies que describe Linneo en su Sistema de la Naturaleza quando no se hallan dibujadas en los libros de Klein y de Argenville a que suele referirse. Sírvase $\mathrm{Vm}$. hacer presente todo esto a la $\mathrm{Acad}^{\mathrm{a}}$ para que vea lo que conviene mandarme en este asunto y lo que puede alcanzar mi obed ${ }^{\mathrm{a}}$. De cualquier suerte será preciso se me informe del fin que lleva en solicitar este catalogo para proporcionar a él mi método etc... ${ }^{94}$

Otra de las aficiones que cultivó Carbonel, de forma paralela a sus obligaciones docentes, y en la que gozó asimismo de cierto predicamento fue la Numismática, actividad a la que ya se había dedicado su padre, el comisario ordenador de Marina Juan Agustín Carbonel Bonfigli, de quien José heredó una rica colección que, según

93. Así se recoge en MÉndez, Fr. F.: Noticias sobre la vida, escritos y viajes del Rmo. P. Mtro. Fr. Enrique Flórez (...), por Fr.---, segunda edición que con notas y adiciones publica la Real Academia de la Historia, Madrid, 1860, pp. 265-266.

94. José Carbonel a Lorenzo Diéguez, Cádiz, 23 de enero de 1767, RAH, leg. 11-8046, exp. Pedro Sinnot (1762-67). El subrayado está en el original. 
testimonio de su hijo Antonio Carbonel Borja, acrecentó con el paso de los años. Este Antonio Carbonel, profesor del Seminario de Nobles, anticuario de los Reales Estudios de San Isidro y conocido numismático, fue un personaje ciertamente peculiar, algo fatuo y de escasa brillantez intelectual. En 1804, mantuvo una curiosa disputa epistolar con el párroco de la localidad de Escalonilla, Luis Carlos Zúñiga, que se ventiló públicamente en las páginas del diario Efemérides de España ${ }^{95}$, donde hacía alusión a la colección de monedas poseída por su padre:

Es menester suponer, que no tengo noticia, de que otro alguno en España, haya visto tantas medallas como yo, ni que haya sido instruido expresamente por un padre como el mío, tan conocido por su literatura. Y para que ayudase la práctica a la teórica, compró este señor la colección de medallas de D. Luis de Velázquez, la que aumentada y unida á la del Marqués de la Cañada, está actualmente en la Real Academia de la historia. ${ }^{96}$

Un año después, el canónigo de Tarragona y gran amigo de Jovellanos, Carlos González de Posada, colocaba a José Carbonel entre los principales coleccionistas del siglo XVIII aunque, malinterpretando sin duda el testimonio anterior, afirmaba que dicho Carbonel había comprado no sólo la colección del marqués de Valdeflores sino también la que había pertenecido al marqués de la Cañada ${ }^{97}$, lo cual era inexacto pues esta última fue adquirida por la Academia de la Historia en 1769, interviniendo Carbonel exclusivamente como intermediario entre ambas partes, y así queda demostrado en el medio centenar de documentos de que consta el expediente de adquisición ${ }^{98}$. A su vez, y por lo que respecta a la colección de Valdeflores, nada hemos podido constatar respecto a si fue comprada efectivamente por el viejo Carbonel aunque, de ser cierta dicha afirmación, su destino habría sido también el de nutrir los fondos de la Academia pues esta institución adquirió con posterioridad el monetario de Carbonel como así hizo constar en 1805 al hacer la relación de los académicos fallecidos en los años anteriores:

95. Un testimonio negativo sobre Antonio Carbonel Borja en 1798 como profesor de Historia y bibliotecario del Seminario lo recoge Desdevises du DeZerT, G.: La España del Antiguo Régimen, Madrid, 1989, p. 760, según el cual el dicho Carbonel «es un hombre poco instruido y descuidado, se duerme en clase, acepta dulces e incluso dinero de los alumnos, ha vendido libros de la Biblioteca, pero sirve de espía al Director».

96. Concluye la nota del señor Carbonell, en respuesta al señor Zúñiga, en Efemérides de España, lunes 6 de agosto de $1804, n^{\circ} 219$, p. 893. Las respuestas de Carbonel dieron pie a la publicación de un impreso satírico titulado Carta de Pantaleón Claros a D. Antonio Carbonell y Borja, felicitándole por sus descubrimientos numismáticos, escrita desde Parla a 12 de agosto de 1804, Madrid en la Imprenta Real, año de 1804; en donde se ridiculizaban sus desafortunadas expresiones, su estilo pomposo y sus torpes argumentos.

97. GonZÁlez de PosAdA, C.: «Noticia de españoles aficionados a monedas antiguas» (1805), publicado en Boletín de la Real Academia de la Historia, T. LI (1907), pp. 452-484 (la referencia a la colección de Carbonel en p. 469).

98. Dicho expediente se conserva en RAH, Gabinete Numario (GN) 1769-1770/1 (1-52). 
También han faltado no pocos de los sujetos que por su afición a las letras merecieron ser contados entre sus individuos honorarios. Tales han sido el señor D. Josef Carbonell; cuyo precioso monetario adquirió la Academia. ${ }^{99}$

\section{PROYECTOS Y COLABORACIONES. LA DIRECCIÓN DE LOS ESTUDIOS GADITANOS}

Carbonel fue un trabajador entusiasta que mostró siempre su absoluta disposición a colaborar en todos aquellos proyectos en los que podían resultar de utilidad sus conocimientos, ya se emprendiesen por instituciones o esferas gubernamentales, como la Academia de la Historia, el Seminario de Nobles o el Consejo de Castilla, ya fuesen simples particulares quienes acudían a él solicitando su ministerio.

La Academia, que en 1759 había premiado su incansable dedicación con el ascenso a la categoría de académico supernumerario ${ }^{100}$, recurrió a él en ocasiones, unas veces encomendándole la traducción de inscripciones o la elaboración de informes, y otras solicitando su asesoramiento e intermediación en la compra de monedas o libros. Así sucedió en 1768 y 1769 con los monetarios del comisario ordenador Estrada y del marqués de la Cañada, en cuyas compras intervino Carbonel $^{101}$, y en marzo de 1781 cuando, con ocasión de haber apresado la escuadra de Luis de Córdoba el año anterior un convoy de barcos ingleses en Porto Santo, se puso a la venta en Cádiz un importante lote de libros de geografía, historia y viajes que formaban parte del botín incautado y de cuya compra también quedó encargado Carbonel ${ }^{102}$.

Hubo también ocasiones en las que la posible intervención de Carbonel se malogró, algunas veces sin llegar a tener noticia de ellas. Esto sucedió, por ejemplo, con el ambicioso proyecto de Benjamín Kennicott de colacionar el mayor número posible de códices hebreos manuscritos existentes en archivos y bibliotecas para, tras recoger y comparar las diferentes variantes, editar el texto puro hebreo de la Biblia. En este sentido, se conserva una carta dirigida por el padre Martín Sarmiento a Campomanes, fechada en marzo de 1764, en la que explicaba los pormenores del proyecto así como la existencia, en su convento de San Martín, de un hermosísimo y voluminoso códice hebreo que contenía la mitad de la Biblia. Colacionar el texto era una tarea ímproba que requería mucho tiempo y paciencia por el tamaño del ejemplar y la gran cantidad de caracteres y acentos que contenía, pese a lo cual el representante en España de Kennicott estaba dispuesto a pagar el trabajo de quien quisiese realizarlo. A los ojos de Sarmiento, la persona idónea para efectuarlo era Carbonel pero sus circunstancias pro-

99. Memorias de la Real Academia de la Historia, T. IV, Madrid, 1805, p. XXII.

100. En RAH, Expediente de José Carbonel y Fogasse, Leg. 129, carp. 45, sección 11D, n 29, se conserva una carta escrita desde Cádiz el 4 de julio de 1759 y dirigida a Eugenio Llaguno, secretario de la Academia, en la que Carbonel agradece su ascenso a supernumerario.

101. RAH, Gabinete Numario (GN), 1768/1 (1-5) y GN, 1769-1770/1 (1-52).

102. RAH, Expediente de José Carbonel y Fogasse, leg. 129, carp. 45, sección 11 D, (1781-1782) Cartas sobre libros ingleses (1-18) La correspondencia entre Carbonel y la Academia por este motivo se inició el 17 de marzo de 1781 y se prolongó hasta el 13 de mayo de 1782. 
fesionales y el alejamiento en el que se encontraba -según comentaba a Campomanesle imposibilitaban para ello:

En conclusión le dixe que yo no sabía de cierto quien quisiese entrar en ese trabajo tan penoso. Y se despidió. Acordeme que D. Francisco Baier, canónigo de Toledo, era capaz para esa obra, pero dudé que quisiese. También me acordé de D. Joseph Carbonel, que está en Cádiz, a quien V.S . conoze bien y sabe que es capaz de poder, y de querer. Pero como está en Cádiz, no querrá venir a Madrid, sino se lo manda quien pueda; y sólo en caso de venir a otras diligencias, acaso entraría de buena gana a hazer la colación del dicho códice. ${ }^{103}$

Dos años después era Carbonel quien ofrecía su colaboración a la Academia de la Historia. Se trataba en esta ocasión del proyecto presentado en 1762 por el capellán irlandés Pedro Sinnot para traducir el Diccionario Universal de John Barrow ${ }^{104}$, obra esta última que pretendía ampliar y corregir la enciclopedia o diccionario de Ephraim Chambers ${ }^{105}$. La Academia, tras haber emitido un primer dictamen favorable a la utilidad del proyecto, fue encargada por el Rey de revisar la publicación. En 1765, tras corregir la primera letra, se detectaron algunos fallos en aquellas entradas que trataban materia de religión por lo que Campomanes, en su condición de director, solicitó a destacados científicos españoles como Jorge Juan, su dictamen en cuestiones de Física y Astronomía. La respuesta del marino, bien conocida, fue una firme declaración a favor del sistema newtoniano ${ }^{106}$. Carbonel conoció este proyecto en 1766 a través de Jorge Juan pero, creyendo equivocadamente que se trataba de traducir el diccionario de Chambers, alertó a la Academia sobre determinados errores en los que incurría dicha obra, ofreciendo incondicionalmente a la institución sus conocimientos y su biblioteca:

El Sr. Dn. Jorge Juan, mi comandante, me ha dicho estaban Vds. trabaxando en una traducción del Diccion ${ }^{\circ}$ Encyclopédico de Chambers. Es empresa digna del celo de la Academia y cuya ejecución puede traer grandes ventajas a la Nación, pero debo prevenir a Vms. que conviene verificar en $\mathrm{qt}^{\circ}$ sea posible los passages de Autores que trahe porque he visto que cita en falso la Bibliotc ${ }^{\text {a }}$ Oriental de Herbelot en la voz Álgebra cuya equivocación ha inducido en error a los Encyclopedistas de París, que siguieron a Chambers sobre su palabra. El Diccionario de Trevoux no ha caido en essa falta y por esso cita a dicha $\mathrm{B}^{\mathrm{a}}$ Oriental a derechas. Con este motivo creo también ser de mi obligación ofrecer a

103. El padre Sarmiento a Pedro Rodríguez Campomanes, San Martín 8 de marzo de 1764, en FUE, APC 48/124. Cfr. en Avilés Fernández, M. y Cejudo López, J. (eds.): op. cit., pp. 100-101 (la cita a Carbonel en p. 101). También se encuentra esta carta en SIMÓN DíAZ, J.: «El Padre Sarmiento en los Archivos de Campomanes y de Silos: seis cartas más», en Estudos adicados a Fr. Martín Sarmiento. Artigos tirados dos «Cuadernos de Estudios Gallegos» (1945-1982), Santiago de Compostela, 1995, pp. 333-334.

104. BArrow, J.: A New and Universal Dictionary of Arts and Sciences, London, 1753. El proyecto de Pedro Sinnot está tratado en profundidad por Velasco MoRENO, E.: «Pedro Sinnot: la obra intelectual de un clérigo irlandés en España», en VILLAR GARCÍA, $\mathrm{M}^{\mathrm{a}} \mathrm{B}$. (coord.): La emigración irlandesa en el siglo XVIII, Málaga, 2000, pp. 230-243.

105. Chambers, E.: Cyclopaedia or an Universal Dictionary of Arts and Sciences, London, 1728.

106. Jorge Juan a Pedro Rodríguez Campomanes, Madrid 7 de noviembre de 1765, en RAH, leg. 11/8046, exp. Pedro Sinnot (1762-1767). 
la Academia mis cortos servicios; tengo a Chambers, Herbelot, Trevoux, Morera y Jarvis (Diccion ${ }^{\circ}$ Mathem $^{\circ}$ Physico \&) mediante cuyos auxilios, el de la lengua Ynglesa y la inteligencia en las Mathemas podré quizas servir para la explicación y equivalencia de alguna voz o phrase cientifica de dicho Diccion ${ }^{\circ}$ si el traductor no es facultativo, etc. Amigo mío, ofrezco lo que puedo y siento no tener otra cosa con que brindar a la Academ ${ }^{\mathrm{a}}$ en prueba de mi afecto y veneración. ${ }^{107}$

Finalmente, aclarado el error de Carbonel, reiteró éste su ofrecimiento sin que quede constancia en el expediente de que fuera aceptado por la Academia la cual, por otro lado, dilató de tal modo el proceso de revisión del manuscrito de Sinnot que no llegó a concluirlo jamás.

Menos de seis meses después, en abril de 1767, se produjo la expulsión de los jesuitas de todos los territorios de la Corona española, acontecimiento que deparó a Carbonel una nueva ocupación, que vino a sumarse a las que ya desarrollaba, y nuevos quebraderos de cabeza.

En Cádiz, la enseñanza pública había estado encomendada a los miembros de la orden ignaciana desde que en 1566 los cabildos catedralicio y municipal acordaron costear los gastos de una escuela regentada por aquéllos. Tras la expulsión, el Consejo de Castilla -actuando, sin duda, por influjo de Campomanes que era a la sazón fiscal del mismo- nombró a Carbonel director de los estudios públicos gaditanos ${ }^{108}$. Fue ésta una designación que colmó de orgullo al interesado y que desempeñó con verdadero entusiasmo. Muy pocos meses después de producido el extrañamiento, ya encontramos en su correspondencia con Campomanes evidentes muestras de que trabajaba intensamente en la renovación de las enseñanzas que hasta ese momento habían corrido a cargo de los jesuitas, teniendo prácticamente ultimado un Plan de Estudios, destinado a regir la futura Casa de Educación de Cádiz, el cual -según anunciaba a Campomanes a finales de octubre de 1767- estaba a punto de serle enviado:

Esta mañana he vuelto a ver al Cavallero Gobernador y à su Assesor, quienes han aprobado todas mis ideas, y me han prometido enviar el correo que viene al Consejo mi Plan de Estudios para esta futura Casa de Educación. Me he alegrado mucho de sus demoras, que me dan lugar a recibir las correcciones de Vm al Ensayo de dicho plan, que tuve el honor de remitirle el día 20 del corriente. Yrá dirigido a Vm con una carta de oficio, como se debe a tan alto y respetable Magistrado. ${ }^{109}$

En esa misma carta remitía a Campomanes un Método de enseñar las lenguas Griega, Hebrea, Caldea y Siríaca obra que, según le explicaba, había compuesto a

107. José Carbonel a Lorenzo Diéguez, Cádiz 23 de diciembre de 1766, en RAH, leg. 11/8046, exp. Pedro Sinnot (1762-1767). El subrayado está en el original.

108. Espigado Tocino, G.: Aprender a leer y escribir en el Cádiz del ochocientos, Cádiz, 1996, pp. 65-66. Bustos Rodríguez, M.: «Los siglos decisivos», en Lomas Salmonte, F. J. et alii: Historia de Cádiz, Cádiz, 2005, p. 459.

109. José Carbonel a Pedro Rodríguez Campomanes, Cádiz 30 de octubre de 1767, en FUE, APC 23/35-1. Cfr. en AvilÉs, M. y CEJUDO, J. (eds.): op. cit., pp. 173-174. 
instancias del canónigo Cristóbal Conde ${ }^{110}$, cuando ocupó la cátedra de Griego que se abrió en el Sacromonte de Granada, y que llevaba varios años durmiendo en un cajón. Pero ahora, al parecer, Campomanes se hallaba «empeñado en sacar con lucimiento a su amigo y servidor», y había alguna posibilidad de que dicho manuscrito se publicase, por lo que Carbonel le rogaba que lo revisara cuidadosamente y pasara «ya la esponja y ya la lima en lo que necessitare corrección, si la obra lo merece, para el bien público, el honor de la Academia, y el de Vm en particular», ofreciéndose además a elaborar otros métodos para la enseñanza del latín y las lenguas vivas.

Por razones que desconocemos el método de Carbonel para la enseñanza del griego no fue publicado, sino que permaneció mezclado entre los papeles de Campomanes durmiendo un largo sueño del que no despertaría hasta doscientos años después ${ }^{111}$. Tampoco hay constancia de que llegara a publicarse el método de latín que se mostraba dispuesto a elaborar aunque, cuando en 1785 redactó su solicitud de jubilación -tras enumerar las obras que había compuesto en el desempeño de su labor como maestro de pajes, maestro de Guardias Marinas y miembro de la Asamblea Amistosa Literaria respectivamente, a todas las cuales hemos hecho referencia en los capítulos correspondientes-citaba además «un método para el estudio de la latinidady un tratado elementar de Cosmografía» que, según manifestaba, le había sido solicitado por el entonces director del Seminario de Nobles, Vicente Doz para uso de dicha institución ${ }^{112}$. En ese

110. El canónigo de la catedral de Málaga, Cristóbal Conde (o Medina Conde, como falsamente se denominaba él mismo) fue uno de los imputados, junto con el prebendado de la catedral de Granada, Juan de Flores Oddouz, y el clérigo Juan de Echeverría, en el célebre proceso de las falsificaciones de la alcazaba de Granada, que se inició en 1774 a raíz de los polémicos descubrimientos arqueológicos que desde 1754 se venían realizando en dicho lugar por los acusados, y que culminó en 1777 mediante sentencia que les condenaba como autores de falsificar documentos del Voto de Santiago, monumentos religiosos y civiles antiguos, escrituras públicas y libros. En el proceso salió a relucir la relación epistolar mantenida por dicho Cristóbal Conde con diferentes eruditos entre los que se encontraba José Carbonel, quien había manifestado sus reparos a los descubrimientos citados y así se recoge en el proceso: «Aquellas correspondencias con los eruditos de España, que se embargaron en la casa de D. Christobal Conde, y a las que se refiere en sus declaraciones, son una carta de Don Joseph Carbonel, Académico de Sevilla, del mes de septiembre de 1770, en que se producen varias censuras contra los monumentos de la Alcazaba, recordando la sospecha de algunos eruditos, de que Don Juan de Flores componía de noche lo que interpretaba de día». El resumen del proceso se encuentra en Razón del juicio seguido en la ciudad de Granada ante los Ilustrísimos Señores Don Manuel Doz, presidente de su Real Chancilleria; Don Pedro Antonio Barroeta y Ángel, arzobispo que fue de esta diócesis y Don Antonio Jorge Galbán, actual sucesor en la Mitra, todos del Consejo de su Magestad; contra varios falsificadores de escrituras públicas, monumentos sagrados, y profanos, caracteres, tradiciones, reliquias y libros de supuesta antigüedad, Madrid MDCCLXXXI, por D. Joachin Ibarra, Impresor de Cámara de S.M., con superior permiso.

111. El manuscrito inédito del Método de Carbonel se conserva en FUE, APC 23/35 y ha sido estudiado por Hernando, C.: Helenismo e Ilustración (el Griego en el siglo XVIII español), Madrid, 1975, pp. 100103. Se encuentra transcrito en pp. 321-326.

112. Vicente Doz fue nombrado director del Seminario de Nobles el 14 de septiembre de 1774 y desempeñó el cargo hasta el 28 de noviembre de 1781, en que falleció. Cfr. en ANDúJar CASTILLO, F.: 
mismo escrito también hacía mención de otros trabajos que había realizado a instancias del Consejo de Castilla:

Ha desempeñado con la del Consejo Extraordinario varios encargos en que se dignó comisionarle, que fueron, la formación de un plan de estudios para el Seminario que V. Magestad había mandado establecer en el Colegio, que fue, de los Regulares extinguidos de Cádiz; un Ynforme sobre el modo de hacer florecer, en la Universidad de Salamanca el estudio de las Lenguas Hebrea y Griega; y los exámenes de varios métodos de estudios que se habían presentado a aquel tribunal. ${ }^{113}$

Y aún encontramos referencias a otra obra suya en las mismas cartas en las que Carbonel informaba a Campomanes sobre el proceso de venta del monetario del marqués de la Cañada y los pormenores acaecidos en la puesta en marcha del nuevo colegio gaditano. Tras resumirle los avances efectuados en ambos procesos le anunciaba el inminente envío de una gramática de la lengua castellana que había compuesto para uso de ese centro:

En las próximas vacaciones podré sacar y remitir a Vm una copia de los Elementos de Gramática General y Castellana, que he dispuesto para este Colegio; y si pareciesen bien, se servirá Vm avisármelo por sí o por el Secretario de la Academia, para que puedan imprimirse aquí con mi nombre, y el título de Académico, de que no puedo usar en obra alguna, que no esté aprobada por la misma. ${ }^{114}$

Pero, contrariamente a sus deseos, en marzo del año siguiente todavía no había podido concluir la obra por habérselo impedido sus diferentes ocupaciones ${ }^{115}$, siendo esa la última mención al asunto que existe en el epistolario por lo que no sabemos si Carbonel finalizó su gramática o si, tras remitírsela a Campomanes, no mereció el visto bueno de la Academia. En cualquier caso, tampoco esta obra llegó a la imprenta.

Mención aparte merece su actividad como director de los estudios públicos de Cádiz, cargo desde el que impulsó un plan de reforma de la enseñanza que fue aprobado por el Consejo de Castilla pero en el que hubo de superar los numerosos obstáculos y reticencias que continuamente encontraba por parte de algunos individuos disconfor-

«El Seminario de Nobles de Madrid en el siglo XVIII. Un estudio social» en Cuadernos de Historia Moderna. Anejos, 2004, III, pp. 201-225.

113. AGMAB, Intendencia, leg. 3268/48: Expediente personal de José Carbonel Fogasa, instancia de José Carbonel solicitando la jubilación, Isla de León 2 de junio de 1785. En la Biblioteca Nacional, Mss. 11552, fol. 135 y ss. se conserva el Informe al Real Consejo de Castilla sobre los medios de hacer florecer en la Universidad de Salamanca el estudio de las lenguas Griega y Hebrea, por D. Jph. Carbonel de la Real Academia de la Historia, Director de los Reales Estudios de Cádiz y Comisario de Marina. Está fechado en 9 de julio de 1768.

114. José Carbonel a Pedro Rodríguez Campomanes, Isla de León 22 de diciembre de 1769, en RAH, GN 1769-1770/1 (8). Todos los comentarios de Carbonel relativos a su actividad como director de los estudios gaditanos y a las reformas acometidas durante estos primeros años, se encuentran en la correspondencia mantenida con Campomanes y José Miguel de Flores, secretario de la Academia, durante el proceso de compra del monetario del marqués de la Cañada.

115. José Carbonel a Pedro Rodríguez Campomanes, Isla de León 6 de marzo de 1770, en RAH, GN 1769$1770 / 1(17)$. 
mes con las nuevas directrices. Su labor abarcaba desde la supervisión y dirección de las obras necesarias para acondicionar el viejo edificio que antes ocupaban los jesuitas e instalar en él una casa-colegio donde alojar a medio centenar de niños con sus maestros, capellanes y $\operatorname{criados}^{116}$, hasta la organización de la dinámica docente y la celebración de exámenes y oposiciones, como las que se celebraron en julio de 1769 para cubrir las vacantes de las Cátedras de Latinidad y Retórica existentes en dicho colegio. En esta ocasión, Carbonel supervisó el correcto desarrollo de las mismas para lo cual decidió aplicar el sistema establecido para los certámenes en las academias militares de Guardias Marinas, Ingenieros y Artilleros, con cuyo meticuloso procedimiento -que, según detalló a Campomanes, consistía en que los propios opositores se examinaban unos a otros- garantizaba los mejores resultados y evitaba quejas y murmuraciones ${ }^{117}$. También podemos señalar, a título de curiosidad, que Carbonel formó parte del tribunal, junto con Fr. Pedro Rodríguez Mohedano y los marinos Vicente Tofiño y Juan Lombardón, que en 1768 examinó a $\mathrm{M}^{\mathrm{a}}$ del Rosario Cepeda Mayo, niña de tan sólo doce años hija de un regidor gaditano, la cual haciendo alarde de una extraordinaria erudición contestó durante tres días a las preguntas que se le formularon sobre Historia, Gramática, Geografía, Geometría, Ortografía, Francés, Latín y Griego; todo lo cual le valió ser nombrada regidora honoraria de Cádiz ${ }^{118}$.

En otro orden de cosas, Carbonel consiguió suprimir, de acuerdo con la autoridad eclesiástica, la procesión anual que en honor de la Inmaculada Concepción realizaban los jesuitas con los alumnos de las Escuelas Pías, a los que hacían desfilar vestidos para la ocasión con costosos uniformes militares y gran profusión de tambores y banderas, todo lo cual suponía únicamente un enorme dispendio para los padres, hacía perder tiempo a los niños apartándoles del estudio y les infundía pasión por las galas, alardes y distracciones militares. Decidido a terminar con los referidos excesos y gastos abusivos e innecesarios, estableció que los niños acudieran a los actos religiosos propios de la festividad sin uniformes ni ornatos «logrando así ver reformada una función tan prophana como inútil y perjudicial» ${ }^{119}$.

116. José Carbonel al secretario de la Academia de la Historia, Isla de León 19 de julio de 1770, en RAH, GN 1769-1770/1 (31).

117. José Carbonel a Pedro Rodríguez Campomanes, Isla de León 25 de julio de 1769, en RAH, GN 1769$1770 / 1$ (6).

118. Espinosa de los Monteros, M.: Relación de los ejercicios literarios que la Señora Doña María del Rosario Cepeda y Mayo, hija de Don Francisco de Cepeda y Guerrero... y de la Señora Doña Isabel Mayo, actuó los días 19, 22 y 24 de septiembre del presente año..., Cádiz, Impresor Real de Marina, 1768. Tras el certamen, Francisco Cepeda, padre de María del Rosario pretendió el ingreso de su hija en la Real Academia Española como socia honoraria, solicitud que fue rechazada «por no haber ejemplar ni permitirlo los Estatutos». Cfr. en Álvarez DE MiRANDA, P.: «¿Una niña en la Academia? El caso de María del Rosario Cepeda y su orgulloso padre», en Boletín de la Real Academia española $n^{\circ} 82$ (enero-junio, 2002), pp. 39-45.

119. José Carbonel a Pedro Rodríguez Campomanes, Isla de León 19 de diciembre de 1769, en RAH, GN 1769-1770/1 (7). La actuación de Carbonel, decididamente contraria a los abusos y excesos que conllevaban determinadas celebraciones religiosas, marchaba en consonancia con la actitud que las 
Durante un tiempo pudo compaginar toda esta actividad con sus obligaciones en la Academia de Guardias Marinas pero las cosas se le complicaron cuando, a finales de 1769, se produjo el traslado definitivo desde Cádiz a la Isla de León de todos los efectivos y dependencias de ese Departamento Marítimo. Carbonel estaba obligado a residir en la Isla e impartir allí diariamente sus clases en la Academia mientras que, como director de los estudios gaditanos, se veía precisado a mantener continuas reuniones con el gobernador y los miembros de la Junta Municipal de Cádiz debiendo, asimismo, supervisar las obras de reforma del antiguo edificio de los jesuitas en compañía del arquitecto y el personero.

Sumamente agobiado por el esfuerzo que le suponían tan continuos desplazamientos entre Cádiz y la Isla, Carbonel intentó conseguir a través de Campomanes que se le concediera licencia para poder tener su residencia principal en el colegio gaditano ${ }^{120}$ y solicitó asimismo permiso a Jorge Juan para faltar un día a la semana a las clases de la Academia, proponiendo a un joven sustituto, y poder así dedicarse con más tranquilidad a la dirección de los estudios de Cádiz. Pero sus pretensiones fueron denegadas por el marino ${ }^{121}$ por lo que hubo de proseguir su agotador ritmo de trabajo compaginando todas sus actividades y cumpliendo escrupulosamente con sus obligaciones en la Academia pues de ello dependía, como diría algunos años después, «mi bien estar, mi crédito y la tal qual ventaja que me puedo prometer en el lance de pedir retiro, que se va acercando con los años y débil salud» ${ }^{122}$.

Precisamente ese continuo trasiego entre ambas localidades fue el causante de un nuevo contratiempo que le sobrevino en octubre de 1780 cuando se disponía a trasladar a su domicilio de la Isla varios libros de los considerados prohibidos. Carbonel poseía desde hacía años una licencia verbal para leer dichos libros, concedida por el entonces director de la Academia de la Historia Agustín Montiano, y con ella se había conformado durante todo ese tiempo el comisario de Cádiz; pero en esta ocasión, tras registrarle el paquete que transportaba, le requisó varias obras y, entre ellas, las Acta Eruditorum de Leipzig. El oficial se ofreció a guardárselas durante un año sin remitirlas a Sevilla, comprometiéndose Carbonel a hacer gestiones para conseguir la licencia por escrito y poder recuperar obras tan valiosas y tan necesarias para sus ocupaciones, según exponía al secretario de dicha Academia:

Ya ve V. S. la falta que ésta hace (la licencia) a un Académico, que poseyendo como yo, diversos idiomas, alguna literatura, Matemáticas y Física, y siendo Director de Estudios

autoridades ilustradas comenzarán a adoptar sobre todo a partir del último tercio del siglo XVIII. Ver en este sentido la aportación de Morgado GarcíA, A.: «La reforma de la fiesta religiosa en el Cádiz de fines del siglo XVIII», en este mismo volumen.

120. Ibidem.

121. José Carbonel a Pedro Rodríguez Campomanes, Isla de León 22 de diciembre de 1769, en RAH, GN 1769-1770/1 (8).

122. José Carbonel a Pedro Rodríguez Campomanes, Isla de León 21 de diciembre de 1781, en RAH, Expediente de José Carbonel y Fogasse, leg. 129, carp. 45, sección 11 D, (1781-1782) Cartas sobre libros ingleses (6). 
de la ciudad de Cádiz, y bibliotecario de esta Academia de Marina, está continuamente expuesto a haber de leer y traer de distintas partes y en diferentes lenguas, libros análogos a sus varios estudios y empleos ${ }^{123}$.

Tras ello solicitaba Carbonel que la Academia mediara ante el Santo Tribunal y se le concediera el oportuno permiso, pero diez meses después todavía se lamentaba ante Campomanes del nulo resultado de su petición: «No resuella el Comisario en asunto de mis libros ni sé qué hacer nuevo»» ${ }^{124}$.

\section{¡DIOS NOS MIRE CON MISERICORDIA! LOS AÑOS FINALES}

Un aspecto del que apenas encontramos reflejo en la correspondencia de Carbonel, pero que constituyó una de sus mayores preocupaciones, fue su empeño por conseguir asegurar del mejor modo posible el porvenir de sus hijos, asunto en el que un encadenamiento de desgracias sucesivas malogró las esperanzas que se había forjado para varios de ellos, amargando sus últimos años.

Tuvo, al menos, la satisfacción de poder colocar a su hijo mayor, Antonio Carbonel Borja, como maestro (también bibliotecario) en el Seminario de Nobles de Madrid, cargo que éste consiguió tras pasar varios años mantenido en la Villa y Corte gracias a las cantidades de dinero que le enviaba su padre ${ }^{125}$. Antonio, de cuyas mediocres aptitudes ya hemos hablado páginas atrás, fue también anticuario de los Reales Estudios de San Isidro y autor de varios escritos sobre antigüedades y numismática de los que, al menos uno, titulado Medallas de España ibero-fenicias y latinas no descritas por el Padre Flórez, no pasó la censura de la Academia al considerarlo «falto de plan y mucho más de erudición y necesaria crítica» ${ }^{126}$. Obra suya fue asimismo la traducción de los dos volúmenes de la Encyclopedia Metódica correspondientes a Fábricas, Artes y Oficios $^{127}$, debiendo su colaboración en este proyecto a la decisión expresa

123. José Carbonel a José Miguel de Flores, Isla de León 10 de abril de 1781, en RAH, Expediente de José Carbonel y Fogasse, leg. 129, carp. 45, sección 11 D, (1781-1782) Cartas sobre libros ingleses (3).

124. José Carbonel a Pedro Rodríguez Campomanes, Isla de León 21 de diciembre de 1781 en RAH, Expediente de José Carbonel y Fogasse, leg. 129, carp. 45, sección 11 D, (1781-1782) Cartas sobre libros ingleses (6).

125. Así consta en AHPC-SF, sig. 118, testamento de José Carbonel, Isla de León 11 de junio de 1796, ff. 543-543v $\mathrm{v}^{\circ}$. No sabemos la fecha en que Antonio Carbonel entró de maestro-bibliotecario en el Seminario pero en 1780 ya desempeñaba esa plaza como se desprende del impreso titulado Certamen público de las lenguas griega e inglesa, de la esfera y uso del globo, y de geografía y historia antigua que en este real seminario de nobles tendrán algunos caballeros seminaristas el día (4) de (enero) de 178(1) a las (3 1/2) de la (tarde) baxo la dirección de su maestro D. Antonio Carbonel y Borja. Madrid, Joachín Ibarra, 1780.

126. Cfr. en Aguilar Piñal, F.: Bibliografia de autores españoles del siglo XVIII, T. II (C-CH), Madrid, 1983, p. 212.

127. Carbonel, A.: Encyclopedia Metódica. Fábricas, Artes y Oficios, traducidos del francés al castellano por D.---, Tomo I y II. En Madrid, en la Imprenta de Sancha. Año de MDCCXCIV. Se hallará en su librería en la Aduana vieja. 
de Campomanes, como así reconocía agradecido José Carbonel en carta a su antiguo discípulo y amigo:

Me escribe Antonio que le han asegurado, había sido propuesto por V. para trabajar en la traducción proyectada de la nueva Enciclopedia, de lo que doy a V. las debidas gracias, deseoso de contribuir por este medio indirecto al acierto de tan útil empresa. Mi hijo está determinado a corresponder con el mayor celo y actividad al honor que V. se ha servido proporcionarle. Me alegrára estar inmediato para ayudarle, pero lo haré gustoso en todo lo que permitieren la distancia y la naturaleza del asunto. ${ }^{128}$

En septiembre de 1780, fecha en que José Carbonel otorgó el primero de sus dos testamentos, tanto Antonio como su hermana María se encontraban casados. Menos fortuna había tenido en este aspecto la otra hermana, Elena, quien había estado prometida en matrimonio a un joven para quien Carbonel suplicaba a Campomanes en marzo de 1770: «No eche Vm en olvido al novio de mi hija Helena, de cuya colocación pende en gran parte mi desahogo y sosiego» ${ }^{129}$. Pero la inesperada muerte del muchacho no dejó más opción a su desconsolada prometida que profesar como religiosa en el convento de la Purísima Concepción de la ciudad de Lebrija donde, al carecer completamente de recursos y dado «que aquel convento no da vestuario a sus monjas y dicha mi hija no puede hayudarse con labor alguna a causa de una fluccion havitual en los ojos» ${ }^{130}$ quedó a cargo de Carbonel la obligación de atender con periodicidad a las necesidades de su hija.

Por lo que respecta a Guillermo y Rafael, los dos hijos habidos de su segundo matrimonio, ya quedó dicho páginas atrás que sintieron vocación por la Marina e ingresaron en la Armada, donde sus carreras se truncaron prematuramente al morir ambos en trágicas circunstancias y de manera casi simultánea en el tiempo, aunque en el desempeño de muy diferentes comisiones. El menor de ellos, Rafael, aventurero de la fragata Nuestra Señora del Carmen, falleció el cinco de diciembre de 1779 en el Real Hospital de Oficiales de Brest «de resultas del axetreo y celo con que atendió en aquel Arsenal y mala estación, a la compostura de la fragata Carmen que se le había encargado por su especial inteligencia y actividad» ${ }^{131}$.

128. José Carbonel a Pedro Rodríguez Campomanes, Cádiz 13 de mayo de 1782, en RAH, Expediente de José Carbonel y Fogasse, leg. 129, carp. 45, sección 11 D, (1781-1782) Cartas sobre libros ingleses (18). También se encuentran referencias a ello en JALÓN CALVO, M.: «Sobre la cultura técnica impulsada por Carlos III: La Encyclopedia Metodica como empresa ilustrada» en Investigaciones Históricas. Época Moderna y Contemporánea, $\mathrm{n}^{\circ} 17$ (1997), pp. 101-136.

129. José Carbonel a Pedro Rodríguez Campomanes, Isla de León 6 de marzo de 1770, en RAH, GN 176917701 (17).

130. AHPC-SF, sig. 118, testamento de José Carbonel, Isla de León 11 de junio de 1796, ff. 543-543v .

131. Así lo expone el propio Carbonel en su instancia solicitando la jubilación, AGMAB, Intendencia, leg. 3268/48, exp. de José Carbonel. En la partida de defunción de Rafael, que se encuentra en el Archivo Eclesiástico de la Armada, Lib. 86, f. 22, se hace constar que dicho joven era natural de la Isla de León y, aunque desconocemos su fecha de nacimiento, todo apunta a que cuando murió debía ser menor de edad pues, según se contiene en AHPC-SF, sig. 118, testamento de José Carbonel, Isla de León 11 de junio de 1796, ff. 541-541v, Rafael falleció «de resultas del notorio celo y afán con que procuró desempeñar el 
A su vez Guillermo, teniente de fragata, fue enviado ese mismo año 1779 al golfo de Guinea comandando la zumaca «Nuestra Señora de la Concepción», en auxilio de la expedición del conde de Argelejo que debía tomar posesión de las islas de Fernando Poo y Annobón, cedidas en 1778 por Portugal a la Corona española. Al poco de su llegada a Santo Tomé, Guillermo recibió órdenes de circunnavegar la isla de Fernando Poo, reconociendo sus costas a fin de buscar el lugar más idóneo para establecer el campamento español; viaje exploratorio que inició el 13 de septiembre y concluyó el 6 de octubre de 1779 y en el transcurso del cual descubrió y puso nombre a varias ensenadas, considerando como más apropiada para la colonia que se pretendía asentar una amplia bahía que denominó Concepción ${ }^{132}$. El relato de lo que aconteció con posterioridad se contiene en la instancia presentada en 1785 por su padre solicitando la jubilación donde, tras exponer la trágica muerte de su hijo menor en el arsenal de Brest, señalaba a continuación las circunstancias en las que se había producido la de Guillermo, el cual:

...desapareció en el mismo mes de Xbre. de 79, con la balandra que iba mandando para la costa septentrional de Fernando Po, en solicitud de algunos Negros, que se decía sabían hablar inglés, y por consiguiente podían servir de intérpretes á la nueva Colonia Española con los naturales de su contorno, mediante poseer dicho oficial este idioma, y haber dado ya una vez la vuelta de la misma isla con la expresada embarcación para examinar y sondear sus ensenadas y radas, y que luego se pudiese colocar en el mejor sitio la Colonia, como se efectuó aunque inútilmente por la falta total de subsistencias, ocasionada por la de intérpretes; no siendo poca prueba de la satisfacción que se tenía de aquel desgraciado joven, el haber sido servido V. Magestad promoverle a teniente de Navío dos años después de su desaparición, por si acaso había naufragado en la costa inmediata de Negros y se hallaba todavía vivo. ${ }^{133}$

Tal y como refiere, pese a que la pérdida de ambos hijos debió ser prácticamente simultánea en el tiempo, la circunstancia de que no se pudiera confirmar con absoluta certeza el fallecimiento de Guillermo motivó que legalmente hubieran de transcu-

honoroso encargo que se le había hecho (no obstante sus pocos años) de velar la compostura en aquel Arsenal de la Fragata Real nombrada Nuestra Señora del Carmen donde se hallaba embarcado con cédula también Real en clase de voluntario».

132. Los pormenores de la expedicion de Argelejo en CENCILlo DE PINEDA, M.: El brigadier conde de Argelejo y su expedicion militar a Fernando Poo en 1778, Madrid, 1948. Las referencias a la exploración de Guillermo Carbonel en pp. 129-131. También en GARcía CANTús, D.: Fernando Poo: una aventura colonial española en el África occidental (1778-1900), Valencia, 2004, pp. 47-72.

133. AGMAB, Intendencia, leg. 3268/48, exp. de José Carbonel. Algunos años después, en su testamento de 1796, Carbonel relataba la desaparición de Guillermo, del siguiente modo «en el día dieciséis de septiembre del año pasado mil setecientos setenta y nueve emprendió viaje desde la Ysla nombrada de Fernando Pó en los mares de Guinea, comandando una Balandra, a el ebaqüe de cierta comisión de confianza sin haber tenido hasta de presente la más leve noticia de su destino o paradero ni de su Buque ni menos de el de los demás individuos de la tripulación del mismo, siendo de creer por esta razón y la de un recio temporal que les acaeció la tarde de su salida, de que habrá perecido con la referida embarcación, con cuyo motivo se le dio y declaró por muerto». AHPC-SF, sig. 118, testamento de José Carbonel, Isla de León 11 de junio de 1796, ff. 541-541v. 
rrir varios años hasta que se le declarara oficialmente muerto, por lo que Carbonel y su esposa mantuvieron durante todo ese tiempo la esperanza de que su hijo hubiera podido sobrevivir al naufragio. Dos años después de acaecido el suceso, aún traslucía Carbonel en su correspondencia con Campomanes su desesperación y temor a un desenlace fatal: «Todavía no ha habido noticia de mi teniente de Navio, ni de su embarcación o tripulación ;Dios nos mire con misericordia! \» ${ }^{134}$.

En 1785, agotado tras 42 años de trabajo ininterrumpido al servicio de la Corona y enfermo a causa de los achaques de la edad y del espíritu, José Carbonel dirigió una carta a Carlos III solicitando se le concediera la jubilación con el sueldo entero de que hasta entonces disfrutaba y la graduación de comisario de provincia en atención a que, pese a haber desempeñado sus obligaciones a entera satisfacción de sus superiores, sin haber solicitado licencia alguna, ni molestado al Ministerio con quejas o pretensiones y sin haber sido reprendido jamás:

...ha sido mera desgracia suya el que no se le cumpliese la solemne promesa de graduarle y atenderle al igual de los Maestros de Matemáticas, que se le hizo en Madrid, y de que son testigos los tenientes generales D. Antonio de Ulloa y Marqués del Socorro, que presenciaron y promovieron su translación a esta Academia. En cuya atención y a que el Suplicante se halla ya en los 72 años de su edad, mui lastimados el oído y el pecho y cansada la cabeza, y a que si se hubiesen efectuado las promesas referidas, que por ningún título ha desmerecido, pudiera estar ahora mui adelantado en el honor, como sus compañeros; y también a que hai el ejemplar de que poco después de su llegada a Cádiz, se reformaron el Director y tres Maestros de esta misma Academia con sueldo entero, sin que ninguno hubiese servido tanto tiempo como él, ni tenido padre e hijos muertos en campaña y actual servicio de V. Magestad, ni perdido su salud en el constante ejercicio de su empleo, y de tantas obras útiles de supererogación, que ha trabajado por mero amor a la instrucción pública y al honor de la Nación. ${ }^{135}$

Por todo lo cual, terminaba Carbonel suplicando se le concediera el retiro con el mismo sueldo que a los expresados director y maestros y con el grado de comisario de provincia que equivalía, en alguna medida, a los ascensos que habría podido obtener en el cuerpo general de la Armada. Su solicitud fue apoyada por el comandante de la Compañía de Guardias Marinas y el intendente de Cádiz quienes, al trasladar la instancia al Rey hacían constar expresamente su pesar al tener que verse privados de un hombre «que por su notoria sabiduria ha de costar suma dificultad llenar en parte su hueco» ${ }^{136}$. Pero nada de lo anterior sirvió para que el monarca se mostrara generoso con el viejo maestro pues la resolución del expediente, firmada el 25 de junio de 1785 por el bailío Antonio Valdés, venía a concederle la jubilación con el grado de comisario de provincia pero con tan sólo dos tercios del sueldo que percibía. Todavía dos meses después fue requerido por orden del Rey, mediante un oficio, para que se transfiriera

134. José Carbonel a Pedro Rodríguez Campomanes, Isla de León 21 de diciembre de 1781, en RAH, Expediente de José Carbonel y Fogasse, leg. 129, carp. 45, sección 11 D, (1781-1782) Cartas sobre libros ingleses (6).

135. AGMAB, Intendencia, leg. 3268/48

136. Ibidem. 
sin dilación a Madrid salvo que se lo impidieran sus dolencias. A esta resolución contestó Carbonel disculpando su imposibilidad para emprender el viaje debido a su mal estado de salud y a la persistencia de sus indisposiciones que, lejos de mejorar, únicamente cabía esperar que empeoraran con el paso del tiempo, ofreciéndose no obstante para que:

...si en este país, cuyo benigno temperamento me dexa aún respirar, pudiese ser de alguna utilidad al Real servicio en mi corta esfera de Literatura, pronto estoi a sacrificarle, hasta el último aliento los pocos restos que me dexen libres mis males. ${ }^{137}$

No obstante, y pese a todos sus achaques, aún tendría fuerzas para afrontar un último servicio y así, el primero de enero de 1786 tomaba posesión del cargo de regidor bianual de la población de la Isla de León para ese mismo año y el de 1787, nombrándosele diputado general de Menores y defensor de Ausentes y, en Cabildo celebrado seis días después, se le encomendó además la diputación de Escuelas «para que los maestros a quienes está fiada la enseñanza pública sean aptos y adornados de las oportunas circunstancias» ${ }^{138}$.

Los últimos quince años de la vida de José Carbonel no ofrecen dato alguno de relevancia o al menos no poseemos noticia de ellos. Permaneció en su domicilio de la Isla de León donde, el 19 de enero de 1792, murió su esposa, Anastasia Sánchez Labrador. Cuatro años después, en 1796, otorgó su último testamento en el que hacía constar expresamente que, pese a todos los años transcurridos, todavía se le adeudaban por la Casa Real algunos sueldos atrasados de su etapa como maestro de pajes del Rey; así como otros 2.000 reales de vellón correspondientes a dos meses de sueldo como maestro de idiomas extranjeros de la Academia de Guardias Marinas, que quedaron debiéndosele por muerte del habilitado de dicha compañía D. Lucas García.

Tras disponer del modo acostumbrado su funeral y obra pía, dejaba como herederos de todos sus bienes a sus tres hijos vivos, Antonio, Elena y María; estableciendo además un legado del remanente del quinto a favor de $\mathrm{D}^{\mathrm{a}}$. María Palacios, la persona que desde hacía años se ocupaba de su cuidado:

...mujer lexitima de Diego Tintón, que en la actualidad está en mi casa corriendo con el manejo de ella y asistiéndome en quanto corresponde en mi avanzada edad, devilidad de salud, oído, vista y desgraciada soledad (...) en premio del celo, caridad y pureza con que a pesar de su poca salud y las pensiones de su estado, me está sirviendo de muchos años a esta parte... ${ }^{139}$

La muerte de José Carbonel se produciría cinco años después, en 1801, cuando estaba a punto de cumplir los 94 años de existencia y tras haber sobrevivido a la mortífera epidemia de fiebre amarilla que el verano anterior había asolado Cádiz y que se

137. Ibidem. Oficio al capitán general Luis de Córdoba, 7 de septiembre de 1785; y José Carbonel a Luis de Córdoba, Isla de León 16 de septiembre de 1785.

138. Ayuntamiento de la villa de la Real Isla de León, Actas capitulares años 1786-1787.

139. AHPC-SF, sig. 118, testamento de José Carbonel, Isla de León 11 de junio de 1796, ff. $542 v^{\circ}-543$. 
propagaría rápidamente por los pueblos de la contornada entre los que se encontraba la población de Isla de León donde tenía su domicilio. Ello motivó que, pese a haber dispuesto en su último testamento que quería ser enterrado en la Iglesia Mayor del lugar donde se produjera su fallecimiento, las especiales circunstancias por las que atravesaba la población determinaran que fuera inhumado ese mismo día por la jurisdicción castrense en el depósito común de El Pedroso ${ }^{140}$.

140. Su partida de defunción en la que, como ya dijimos páginas atrás, consta con una edad inferior a la que realmente tenía, se encuentra en APCSFC: Libro de Difuntos nº 3, partida 676, f. 101v.: «En la villa de la Real Isla de León en nueve de febrero de mil ochocientos y uno, se enterró por esta jurisdicción castrense en el depósito común del Pedroso el cadáver de Dn. José Carbonel, Comisario de Provincia honorario del Ministerio de Marina, natural de La Ciutat en la Provenza, Reyno de Francia. Viudo en segundas nupcias de $D^{a}$ Anastasia María Sánchez Labrador. Murió dicho día de edad de ochenta y ocho años. Recivió los Santos Sacramentos. Testó ante Dn. Juan Cordero. Escribano público. Testigos Dn. Juan de Medina y Dn. Juan Lafón. Y para que conste lo firmé dicho dia ut supra. Fr. Juan Sánchez». 